\title{
Design and performance of a robotic arm for farm use
}

\author{
Ali Roshanianfard ${ }^{1,2}$, Noboru Noguchi ${ }^{2 *}$, Tatsuki Kamata ${ }^{2}$ \\ (1. Department of Biosystems Engineering, Faculty of Agriculture and Natural Resources, University of Mohaghegh Ardabili, Ardabil, Iran; \\ 2. Laboratory of Vehicle Robotics, Research Faculty of Agriculture, Hokkaido University, Sapporo 060-8589, Japan)
}

\begin{abstract}
Smart technology which is the backbone of high-efficiency production opens a new horizon in sustainable agriculture. Nowadays, harvesting the heavy-weight crops is considered an arduous job, specifically in Japan which has faced a serious labor shortage in agricultural fields. In this study, a development procedure and evaluation of a 4-degrees-of-freedom articulated robotic arm is presented, and it provides an appropriate infrastructure to develop a smart harvesting robotic system for heavy-weight crops such as pumpkin, watermelon, melon, and cabbage. This robotic arm designed as an actuating unit of a robot tractor for the agricultural outdoor environment. In this regard, different degree of freedom was evaluated under consideration of economic and technical indexes to find an optimized mechanism. The controlling algorithm of the system was developed by consideration of kinematic and dynamic aspects of the real-world condition. A special harvesting methodology was developed based on optimum harvesting conditions. A controlling unit was developed by using PLC system. Experimental performance, accuracy, payload per weight, and repeatability of the system were measured. The payload per weight, overall average accuracy, and overall average repeatability of the robot were $0.21,1.85 \mathrm{~mm}$, and $\pm 0.51 \mathrm{~mm}$, respectively. The results indicated that the developed system had a front access, harvesting length, and workspace volume of $2.024 \mathrm{~m}, 1.36 \mathrm{~m}$, and $8.27 \mathrm{~m}^{3}$, respectively. One of the significant advantages of the proposed robotic arm is its capability to use in different industries with minimum modifications.
\end{abstract}

Keywords: agricultural robot, robotic arm, harvesting, modeling, simulation, design

DOI: $10.25165 /$ j.ijabe.20191201.3721

Citation: Roshanianfard A, Noguchi N, Kamata T. Design and performance of a robotic arm for farm use. Int J Agric \& Biol Eng, 2019; 12(1): 146-158.

\section{Introduction}

Over past few decades, the agriculture industry has faced new challenges. Previously, self-sufficiency in food and rural migration to cities were the significant concerns. With the advancement of science, more challenges now threaten this industry. In these between, the main problem is the age distribution of farmers. According to global agriculture statistics, the average age of farmers is 65.9 years in $\operatorname{Japan}^{[1]}$, compared to 55.9 years old in $\mathrm{USA}^{[2]}$, and 52 years old in $\operatorname{Iran}^{[3]}$. With a declining farming population, the majority of farmers are considered "too old" to handle the rigorous demands of the industry. Another issue is utilizing new agricultural technology. Learning how to operate new agricultural equipment requires time and physical effort, not to mention that the work itself is susceptible to unpredictable weather condition. According to the last report from the Statistics Bureau of Japan, the number of laborers continues to decrease, from 20.33 million (30.2\% of total workers) to 13.40 million (3.7\% of total workers) from 1960 to 2013. All those issues have negative effects on agricultural output, which it was 8.47 trillion yen in 2013, down $0.7 \%$ from $2012^{[1]}$. Furthermore, based on the Global Agricultural Productivity report,

Received date: 2017-08-15 Accepted date: 2018-10-09

Biographies: Ali Roshanianfard, Assistant Professor, research interest: vehicle robotics, Email: alirf@bpe.agr.hokudai.ac.jp, ali.roshanian@yahoo.com; Tatsuki Kamata, Master candidate, research interest: vehicle robotics, Email: tatsukama@bpe.agr.hokudai.ac.jp.

*Corresponding author: Noboru Noguchi, Professor, research interest: vehicle robotics. Research Faculty of Agriculture, Hokkaido University, Kita-9, Nishi-9, Kita-ku, Sapporo 060-8589, Japan. Tel: +81-11-706-2569, Email: noguchi@ cen.agr.hokudai.ac.jp. agricultural production needs to increase by $100 \%$ over the next 40 years $^{[4]}$.

These problems represented only some of the challenges that agriculture currently faces. Smart technology is a potential answer aimed to solve this concern. In term of technology, agricultural robotics is capable to solve the issues that farming communities encounter on a regular basis ${ }^{[5]}$. Most of the laboratories have started to study on new generation of agricultural robots. Examples include a multi-arm robotic harvester ${ }^{[6]}$, robots designed to harvest strawberries ${ }^{[7-9]}$, apples ${ }^{[10]}$, white asparagus ${ }^{[11]}$, cherries $^{[12]}$, tomatoes, petty-tomatoes, cucumbers, kiwi and grapes ${ }^{[8,13-16]}$ harvesters. Stationary robots are used for sheep shearing $^{[17]}$, wearable robots are available for agricultural work ${ }^{[18]}$, and robot tractors have been designed for different applications ${ }^{[19,20]}$.

In the past three decades, harvesting robot projects (including 50 projects) mostly focused on apple harvesting ${ }^{[21-23]}$, orange harvesting ${ }^{[23-26]}$, strawberry harvesting ${ }^{[27]}$, and tomato harvesting ${ }^{[28]}$, which cultivate in four production environment such as orchard (32\%), greenhouse $(41 \%)$, indoor (4\%), and open field $(22 \%)^{[29]}$. The number of developed harvesting robots for open filed was only 11 projects, which mostly aimed asparagus ${ }^{[30,31]}$, melon $^{[32,33]}$, Radicchio ${ }^{[34]}$, saffron ${ }^{[35]}$, and watermelon ${ }^{[36]}$ harvesting. From 1992 to 2014, Japan was the pioneer in the development of harvesting robots by 15 projects. Other countries such as USA (7 projects), Italy (5 projects), China (4 projects), France (4 projects), and New Zealand (3 projects) also have considered on different robotic harvesting system ${ }^{[29,37,38]}$. Different factors such as uncontrollable wind, rain, and lighting can make the development procedure of agricultural robot for open field environment, more difficult. Yet another concern is that 
most of the current agricultural robots were designed for light crops and fruits. For the mentioned designed systems, harvesting heavy products, such as pumpkin, watermelon, and melon, still represents really impossible task. In last three decades, only four projects have considered on heavy-weight crops such as watermelon and melon, however, only a few number the mentioned projects commercialized yet ${ }^{[1,39]}$. Harvesting of pumpkin as a fruit (not for seed harvesting) is generally selective harvesting and it have high market demand in Japan. It means that it is not possible to harvest the entire pumpkins at the same time with acceptable quality. In Japan, farmers are challenged to find workers to harvest pumpkin and watermelon. Wearable robots ${ }^{[18]}$ are not helpful in this case, because there are no enough labor to wear them. As another perspective, it is recommended that to change farmer attitudes from "human-based harvesting ( $\mathrm{HBH}$ )" to "human-led harvesting (HLH)". It is expected that the HLH can help to increase farming efficiency by altering harvest methodology towards human decision makers and robot controllers, instead of human workers.

Among the various kinds of robots, robotic arms tend to be more speedy, accurate and efficient ${ }^{[40]}$. Their ability leads processes by higher protection rate than human labor. For the above-mentioned reasons, the harvest of heavy-weight crops requires a special robotic arm to ensure a big payload and acceptable price. Current industrial robotic arms are enough mature to support heavy payloads, but they are not designed for agricultural application with big vibration, oscillation, and outdoor dusty environment ${ }^{[41]}$. A unique approach to solving this issue involves installing a specially designed robotic arm (shock resistance, dust prevented, and low cost) on an agricultural autonomous vehicle such as robot tractor ${ }^{[42]}$. A robotic arm designed for farm use must be able to maneuver toward a final point along an ideal path at a specified velocity ${ }^{[43]}$. Furthermore, it is necessary that the system be modeled and analyzed dynamically ${ }^{[44]}$; it is therefore essential to use forward / inverse kinematics and dynamics ${ }^{[45]}$. This research presents the development process and performance characteristics of a specifically designed 5-degrees-of-freedom (4-DOF robotic arm + 1 -DOF end-effector ${ }^{[46]}$ ) robotic arm mounted on a robot tractor for heavy-weight crop harvesting, in particular, pumpkin and watermelon $^{[47]}$.

\section{Material and methods}

A robotic arm mounted on an unmanned robot tractor (Figure 1a) and intended for use in outdoor conditions such as agricultural fields raises different concerns than one intended for indoor use. It is important to consider the environmental conditions under which the robotic arm will operate. Such factors will determine the base platform of the robot and affect other aspects and components such as power source, actuators, and controlling unit. Determination of agricultural conditions for the robotic arm will foster selection of the best materials and components. Outdoor conditions are not controllable, so the robot must be designed to withstand climate conditions (rain, wind, and sun), wet or muddy terrain, vibration, hot or cold temperature, and light reflection. In the agricultural environment, the mentioned parameters can vary at any moment.

The robotic arm payload capacity is an important parameter that must be fully addressed in the design. In agriculture, the loaded object weight also is not predictable. Therefore, parameters such as torque and inertia, which depend on the loaded object weight, may vary at every moment during harvesting.
Although payload estimation plays a significant role in robotic arm control, this estimation is not a quick access parameter during harvesting. To sustain requirement impacts, other factors such as speed, size, and platform weight must be considered. Subsequently, power source, propulsion system, clearance, maneuverability, and control algorithm must be factored in. Most of the available industrial robotic arms could not meet the requirements of the described application. The typical industrial robotic arm is not suited and should not be used in agricultural task because most of them were designed for a special isolated environment that could not be translated to farm use; each has a specially patterned workspace that can not support a required harvesting surface when the arm attached to robot tractor; all designed for general use with complex algorithm that increases the harvesting cycle time and complexicity (an average of $33 \mathrm{~s}^{[29]}$ ); they optimized for different performance hence they are pricey and heavy; and the pneumatic or hydraulic power sources that drive powerful industrial robotic arms are not suitable for a mobile agricultural robot with limited power source, that is why it would not be appropriate to use an available industrial robot which are not designed for agricultural conditions.

The RAVeBots-1 (robotic arm for vehicle robotics-first generation) shown in Figure 1 is a newly designed articulated robotic arm for outdoor applications, specifically agricultural applications, in terms of material, flexibility, actuator type, power source, rapid reparability, and cost-effectiveness. Quickly changeable components, a controlling methodology that can adapt to complex conditions, and maximum payload per robot weight (PPW) were among the key parameters considered in the design of robotic arm for agricultural application in this study. The specific material in structure and technical bearings provide a shock resistance platform. To design this robotic arm, dust prevented bearings was used and the components covered. The simplified components reduced the manufacturing cost which had provide a low-cost mechanism.

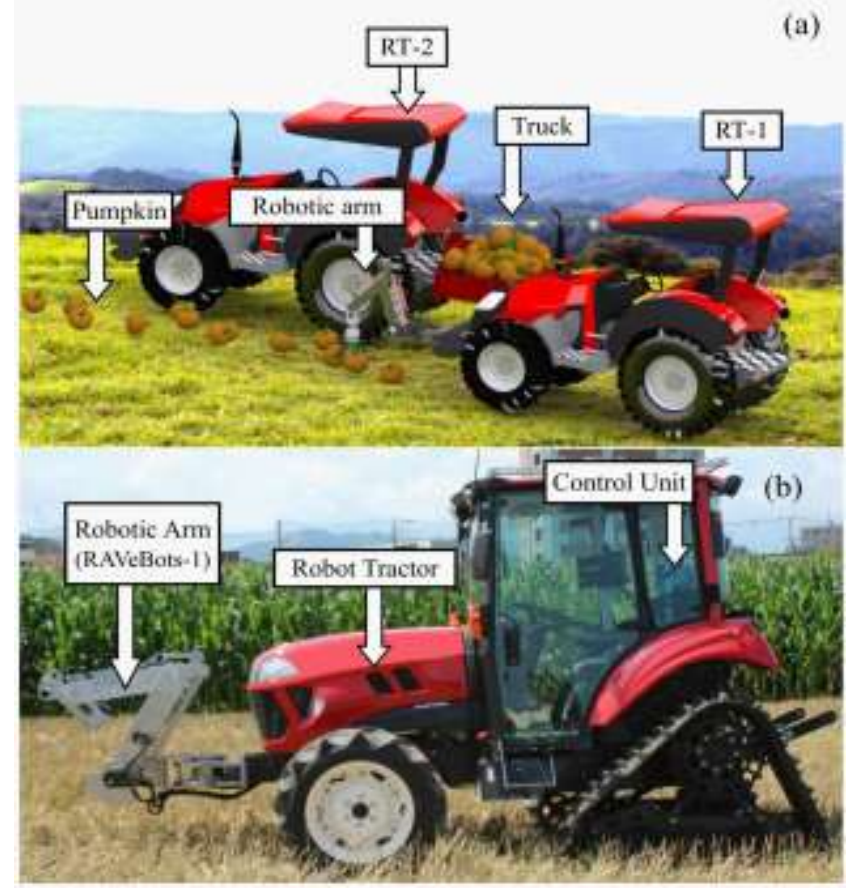

Figure 1 (a) Designed RAVeBots-1 and application illustration, and (b) Developed robotic arm mounted on a robot tractor

Agricultural robots usually consist of three parts: a mobile platform, actuating system, and recognizing system. Figure 1b, 
shows the system developed for this study, consisting of a robot tractor as the mobile platform (developed at the laboratory of Vehicle Robotics of Hokkaido University), the RAVeBots-1 as actuating system for grasping, lifting, cutting, and crop transferring ${ }^{[48]}$, and a control unit. Due to the special methodology used in pumpkin and watermelon harvesting and its required parameters, a 4-DOF was used to design of RAVeBots- 1 because of the minimum economic indexes necessity (section 0). The payload of RAVeBots-1 was designed for almost $25 \mathrm{~kg}$ by $\mathrm{FOS}=2$ (factor of safety). The required values of the robotic arm parameters, including workspace volume $\left(V_{n}\right)$, land surface covered $\left(S_{n}\right)$, front access $(F A)$, and height access $(H A)$ must be maximum, while, the maximum torque value of each joint must be less than mentioned maximum torque of servomotor in datasheet.

The important stages and parameters for designing a new system are structure design, development of controlling unit, and development of controlling algorithm which are described in the following sections.

\subsection{Structure of the robotic arm}

Structure design is the most important stage in the development of a new dynamic system. In this part of the study, one must consider analysis methodology, material selection, boundary conditions, meshing method, and FOS. The standard design process for robotic structures consists of nine main stages: (1) defining the problem; (2) synthesis; (3) creating a prototype model; (4) simulation/calculation/modification; (5) manufacturing of the robot; (6) programming; (7) testing/calibration; (8) final evaluation; and (9) definition of optimal conditions. In this study, the designing procedure of a robotic arm with appropriate degrees of freedom for agricultural application was presented. Based on the analysis results, a 4-DOF robotic arm due to its structural features and cost efficiency was selected (section 0). The components and their assembly models designedby using Solidworks software 2017 (Dassault Systèmes, USA), are shown in Figure 2a. The selected structure was composed to serial links, connected to each other with revolute joints (4R joint structure). Revolute joints were selected as linkage connectors from among collinear, orthogonal, rotational, and twist joints to control the effect of unpredictable forces, vibration, and moment of inertia. All dynamic simulations, motion studies, and other essential parameters were analyzed using Solidworks software. After several modifications, all components were manufactured and assembled based on the final characterization.
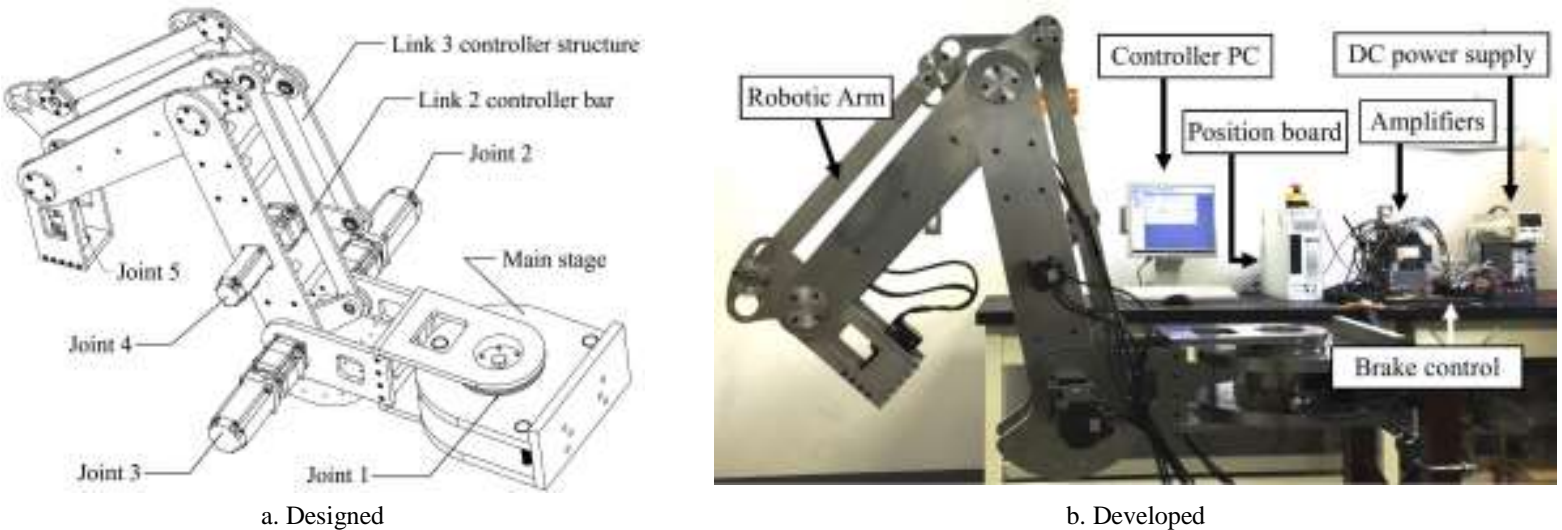

b. Developed

Figure 2 RAVeBots-1 designed, developed

As the RAVebots-1 was intended specifically for a heavy-weight harvesting application, the material likely had a significant effect on robot performance. Therefore, aluminum (AL5052) and steel (ASTM A36) were chosen for structure manufacturing. AL5052 is one of the light alloys of aluminum, with good weldability by gas, arc, and resistance [48]. Figure $2 b$ contains a detailed illustration of the RAVeBots- 1 components, including the developed robotic arm, a PC for programming and controlling with a position board, amplifiers, brake unit, and an emergency switch. The summarized specification of RAVeBots-1 and robot tractor are shown in Tables 1 and 2, respectively.

\section{Table 1 Specification of RAVeBots-1}

\begin{tabular}{lc}
\multicolumn{1}{c}{ Parameter } & Value \\
\hline Maximum payload /kg & 25 \\
Reach /m & 2.024 \\
Number of axes & 5 \\
Degree of freedom (DOF) & (4-DOF robotic arm + 1-DOF end-effector) \\
Power supply & 200ACV \\
Total weight /kg & 119 \\
Type of joints & Revolute joints \\
Material & Aluminum (AL5052), steel (ASTM A36) \\
\hline
\end{tabular}

Table 2 Specification of robot tractor, model Yanmar EG453

\begin{tabular}{|c|c|c|}
\hline \multicolumn{2}{|c|}{ Parameter } & Value \\
\hline \multicolumn{2}{|c|}{ Drive } & 4WD \\
\hline \multirow{3}{*}{ Size } & Length /m & 3.41 \\
\hline & Width /m & 1.54 \\
\hline & Height /m & 2.265 \\
\hline \multicolumn{2}{|l|}{ Weight/kg } & 1895 \\
\hline \multicolumn{2}{|l|}{ Engine } & $53 \mathrm{~kW} / 2300 \mathrm{r} \cdot \mathrm{min}^{-1}$ \\
\hline \multicolumn{2}{|l|}{ Steering } & Hydraulic power steering \\
\hline \multicolumn{2}{|l|}{ Brake } & Wet disc \\
\hline \multicolumn{2}{|l|}{ Gear Box } & I- HMT \\
\hline \multicolumn{2}{|c|}{ Speed $/ \mathrm{km} \cdot \mathrm{h}^{-1}$} & $\begin{array}{c}0.15-32 \text { (Forward) } \\
0.15-24 \text { (Backward) }\end{array}$ \\
\hline \multicolumn{2}{|c|}{ PTO rotation $/ \mathrm{r} \cdot \min ^{-1}$} & $534,758,964,1254$ \\
\hline \multicolumn{2}{|l|}{ Hitch } & Three-point link (JIST) \\
\hline \multicolumn{2}{|c|}{ Maximum front balance weight $/ \mathrm{kg}$} & 150 \\
\hline
\end{tabular}

The PPW, accuracy, and repeatability are important parameters in the case of a new robotic arm development. The PPW of available industrial robotic arms were extracted from their datasheet. This parameter had measured for RAVeBots- 1 after final experimentation. The maximum capability of RAVeBots-1 to lift a weight had set as the maximum payload of this robot. 
These parameters have to measure and optimize after development which is usually provided by the manufacturers, calibration issues, and environmental conditions. Repeatability is a measure of the ability of a robot to consistently reach a specified point, and accuracy is a measure of the distance error associated with the desired point and achieved point ${ }^{[49,50]}$. In this study, two standards were used to determine the accuracy and repeatability including ISO 9283 (1998) and ANSI/RIA R15.05 using a variable speed of operation and maximum payload $(25 \mathrm{~kg})$. These parameters have calculated by using ANSI/RIA R15.05 standard as following equations:

$$
\begin{gathered}
\text { Apx }=\frac{1}{n_{1}} \sum_{i=1}^{n_{1}} \sqrt{\left(\bar{x}-x_{c}\right)^{2}} ; \text { Apy }=\frac{1}{n_{1}} \sum_{i=1}^{n_{1}} \sqrt{\left(\bar{y}-y_{c}\right)^{2}} ; \\
A p z=\frac{1}{n_{1}} \sum_{i=1}^{n_{1}} \sqrt{\left(\bar{z}-z_{c}\right)^{2}} \\
R_{p}=3 \sum_{i=1}^{n_{2}} \sqrt{\frac{\left(L_{i}-\bar{L}\right)}{n-1}}+\bar{L}
\end{gathered}
$$

where,

$$
\begin{gathered}
L_{i}=\sqrt{\left(x_{r}-\bar{x}\right)^{2}+\left(y_{r}-\bar{y}\right)^{2}+\left(z_{r}-\bar{z}\right)^{2}} \\
\bar{L}=\frac{1}{n_{2}} \sum_{i=1}^{n_{2}} L_{i}
\end{gathered}
$$

The accuracy and repeatability experimentations were done in four missions. The missions were four different motion methodologies including (a) circular, (b) rectangular, (c) square, and (d) triangular motions as shown in Figure 3. There were two algorithms, one for circular motion (to move on curves and to reduce inertia, backlash and torque) and second for PTP motion (to move the distance between two points). In the circular motion (Figure 3a), the input commands were included in a center coordination $\left(P_{1}\right)$, radius $(r)$, start angle $\left(-180^{\circ}\right)$, and gain. This motion type was developed for when the robotic arm commanded to maneuver on curves. The gain of movement is the determinative of speed and resolution in this motion. When the gain is high, the calculation consumed time and the resolutions are long and the maneuver speed is low. By controlling the gain value, it is possible to accurately access various positions with desired speed and resolution. The PTP motion was designed for when the robot be commanded to move between two points. In this case a motion on a linear path is not required. The requirement is to be access on each point accurately. As shown in Figure $3 \mathrm{~b}$ and $3 \mathrm{c}$, the input commands include the coordination of four corners $\left(P_{1}, P_{2}, P_{3}\right.$, and $\left.P_{4}\right)$ in square and rectangular motions, and the coordination of three vertices $\left(P_{1}, P_{2}\right.$, and $\left.P_{3}\right)$ in the case of triangular motion. In this regard, 140 experimentations were done in 35 repetitions, static robot tractor, indoor condition and the results were calculated and compared.

\subsection{Control Unit and Algorithms}

The controlling unit of RAVeBots-1 was based on a programmable logic controller (PLC) system. This unit consists of a position board installed on a PC, a controlling program, servo motors, servo amplifiers, and optical cables for data transfer as compact circuits (Figure 4). The PLC systems usually drive a servo motor or a pneumatic/hydraulic cylinder. In this study, the PLC controlled five AC servo motors which was supplied by 200ACV. All other components were selected or developed based on the servo motor properties such as joint torque and moment of inertia. A specific management-control program was developed based on parameters of the servo motor functions. To investigate a controller program, first it is necessary to set some control functions. In case, the control functions were divided into three groups: operational functions (OPF); application functions (APF); and auxiliary functions (AXF). OPF included jogging operation, incremental feeds, linear interpolation, and home-position return. The APF was based on servo speed, acceleration, deceleration, force, torque, limit switch alarm, interlock. The AXF controlled parameters for data reading/writing/changing, monitor functions, sampling, and interruptions. After utilizing the functions, all servo-motor commands are transferred to the position board which be installed on PC's PCI Express protocol. To speed up data transfer, servo motor control signals were sent to the position board via an optical cable. The control-management program was developed using $\mathrm{C}++$. The program included three control modes: torque control mode (TCM), speed control mode (SCM), and position control mode (PCM). The priority of each mode was servo-motor feedback torque, servo-motor feedback speed, and the position of the end effector, respectively. Figure 5 shows functions switched by the "control mode command". Switching to/from PCM to/from SCM/TCM must be done while the motor is off, but it is possible to switch between SCM and TCM any time.
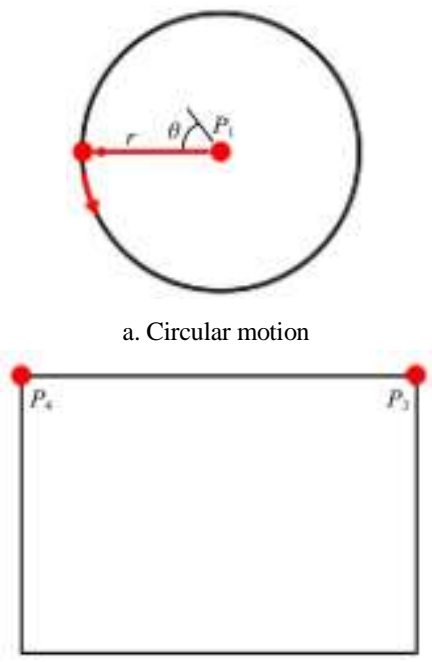

c. Triangular motion

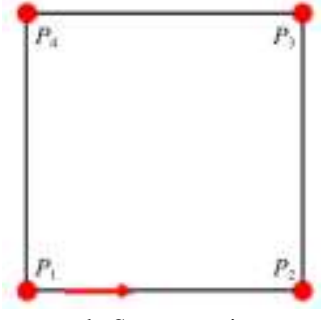

b. Square motion

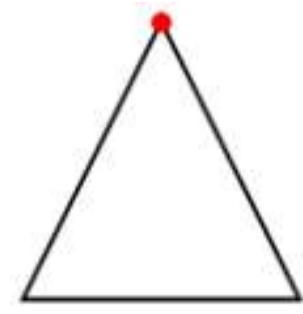

d. Rectangular motion
Figure 3 Defined missions to evaluated accuracy and repeatability of RAVeBots-1

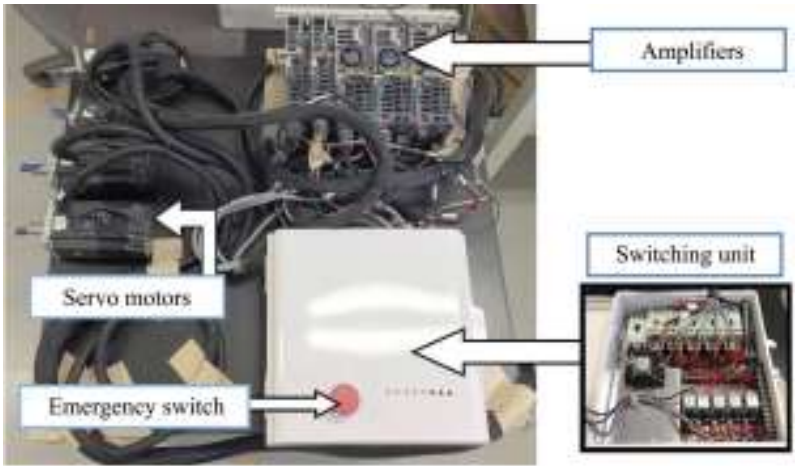

Figure 4 Controlling unit

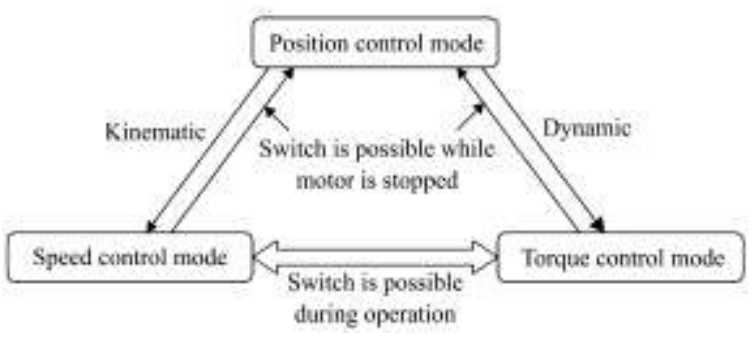

Figure 5 Controlling modes 
The controlling algorithm was developed next. Once an optimized algorithm is determined using kinematic and dynamic modeling, the PLC system parameters can be adopted by algorithm parameters. In robotic arm design, different methods are used to identify optimized controlling algorithms based on robot structure, linkage length, joint angles, and motion limitations. Designing a robotic arm for accurate operations requires actual values for kinematic parameters. Since precise measurement is an expensive and error-prone task, calibration and optimization make the assignment of kinematic parameters easier ${ }^{[51]}$. In this study, both joint and link parameters were needed to be statically and dynamically simulated. Link parameters consisted of link mass, the center of mass, and moment of inertia in different directions; joint parameters included joint angle, angular velocity, and acceleration. The RAVeBots-1's link parameters obtained from a simulation of the designed model in Solidworks software. The manufactured model had approximately $2 \%$ tolerance.

In the design of the controlling algorithm for the RAVeBots-1, the Denevit-Hartenberg method (D-H) was used to find the optimized algorithm $^{[48]}$. The D-H method was chosen because it has a minimum delay and highest accuracy in experiments, and more versatility properties in terms of real-world conditions. The D-H is the accepted method for drawing a free body diagram of a robotic arm, which is based on joint motion, including rotation and translation. Subsequently, the controlling program was developed based on OPF, APF, AXF functions using the D-H algorithm.

Robotic arm kinematics deal with time-dependent/geometry arm motion without consideration of other parameters like force and moment ${ }^{[52]}$. For the analytical study of robotic arm motion, it is best to use robot kinematics. In analyzing the behavior of industrial manipulators, the optimized kinematics model formulation is essential. The kinematics analysis of a robotic arm has two aspects: forward kinematics (FK) and inverse kinematics (IK). Kinematics simulation of RAVeBots-1 was developed by Roshanianfard and Noguchi ${ }^{[48]}$ as shown in Figure 6.

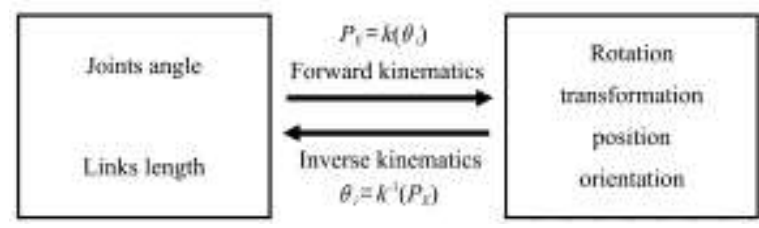

Figure 6 Kinematic simulation parameters

In this case, suppose $P_{E}\left(p_{x}, p_{y} p_{z}\right)$ is the desired target position for the end effector, and $\theta_{i}(i=1, \ldots, 5)$ is the joint angle. It is available a relationship like $P_{E}=k\left(\theta_{i}\right)$, that $k$ is a unique geometric calculation which depends on robotic arm morphology including link length, joint angle ranges, and joint position. Next is the inverse kinematics $(I K)$ which provides a proportional relationship between joint angle and a known position as $\theta_{i}=k^{-1}\left(P_{E}\right)$. It corresponds to finding the appropriate joint angles of each link from a known position in space. For a redundant robotic arms there are infinite answer for $I K^{[53]}$ (Figure 7). As shown in Figure $7 \mathrm{a}$, the $I K$ solutions based on the target coordination can vary in number. Depending on whether the object is located on/in the workspace or outside of it, the $I K$ will have a different number of answers. For the RAVeBot-1 application, it was necessary to provide some limitations and omit unnecessary workspace volume to reach the optimized logical number of answers. Thus, when the structure of RAVeBots-1 developed and mounted on the robot tractor, some rotation limitations applied in each joint to increase the safety and to protect the body against to accidental interferences in during the experiments. In addition, the height access was limited due to robot tractor height $(70 \mathrm{~cm})$. Once the limitations applied, the IK solutions were optimized. In Figure $7 \mathrm{~b}$, the volume $V$ which is located under link-1 and the tractor chassis, was negligible in terms of workspace volume. This is because, when the robot tractor moves, the available pumpkins in $V$ volume be already scanned and harvested in the previous step, so there was no need to rescan it. The optimization of controlling algorithm was done by applied limitations on workspace as shown in Figure $7 \mathrm{~b}$. The system has two kinds of scenarios, (1) the robotic arm can grasp, pick, and lift crop produce located at A or B, or (2) the object is located out of the workspace at $\mathrm{C}$ location, the robot tractor begins to move forward; if a pumpkin be found in the scanned block, the system will start to harvest them, otherwise, it will continue to move one step forward until the end of the harvesting task as shown in Figure 8. The consideration on possible parameter in outdoor field such as delays due to positing sensor, recognition error due to dun radiation, and slipping of the tire, steering control can affect the harvesting process and the possible relationships will be considered in future studies.

The dynamics of a robotic arm must address the actuator torque or force relation by arm motion. In this analysis, it was necessary to consider mass and moment of inertia ${ }^{[52]}$. The dynamic parameters (payload, moment of inertia, etc.) were varied, together with boundary conditions during all phases of manipulation. The boundary conditions were a manipulating mechanism movement in the free workspace and the appearance of dynamical reactions under constrained robot gripper movement in the mechanical assembly and metal machining ${ }^{[54]}$. Forward dynamic

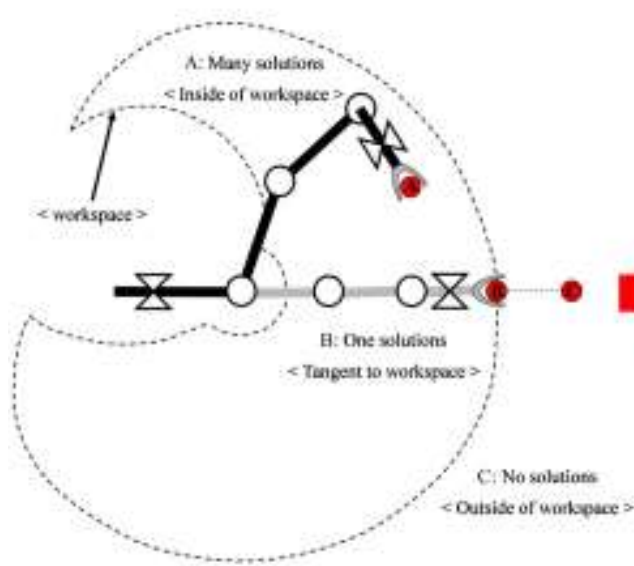

a. Main developed algorithm

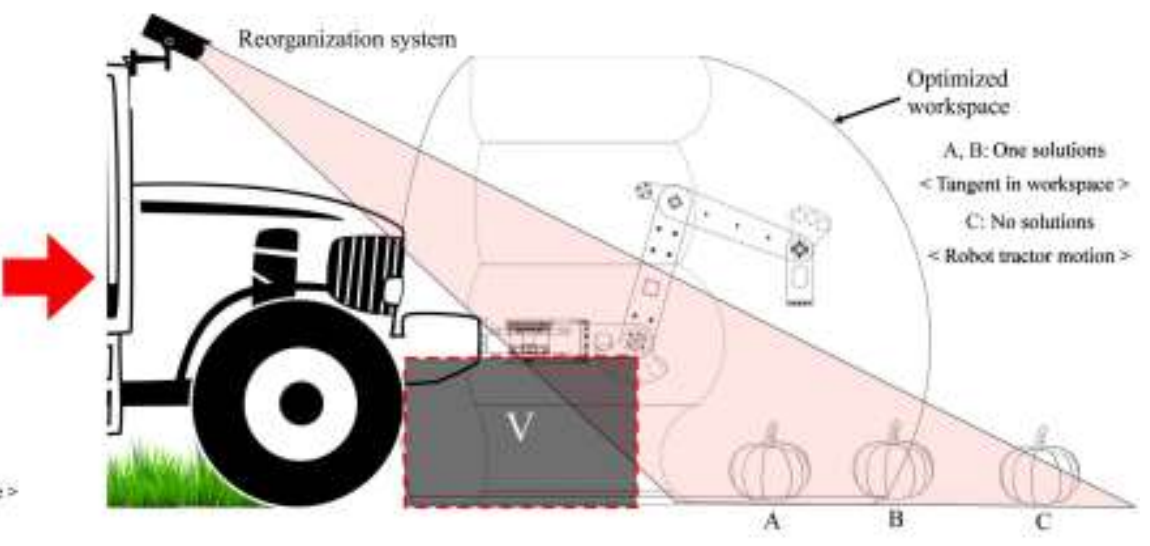

b. Improved algorithm in real-world condition when the robotic arm is installed on robot tractor Figure 7 Kinematic scenarios 


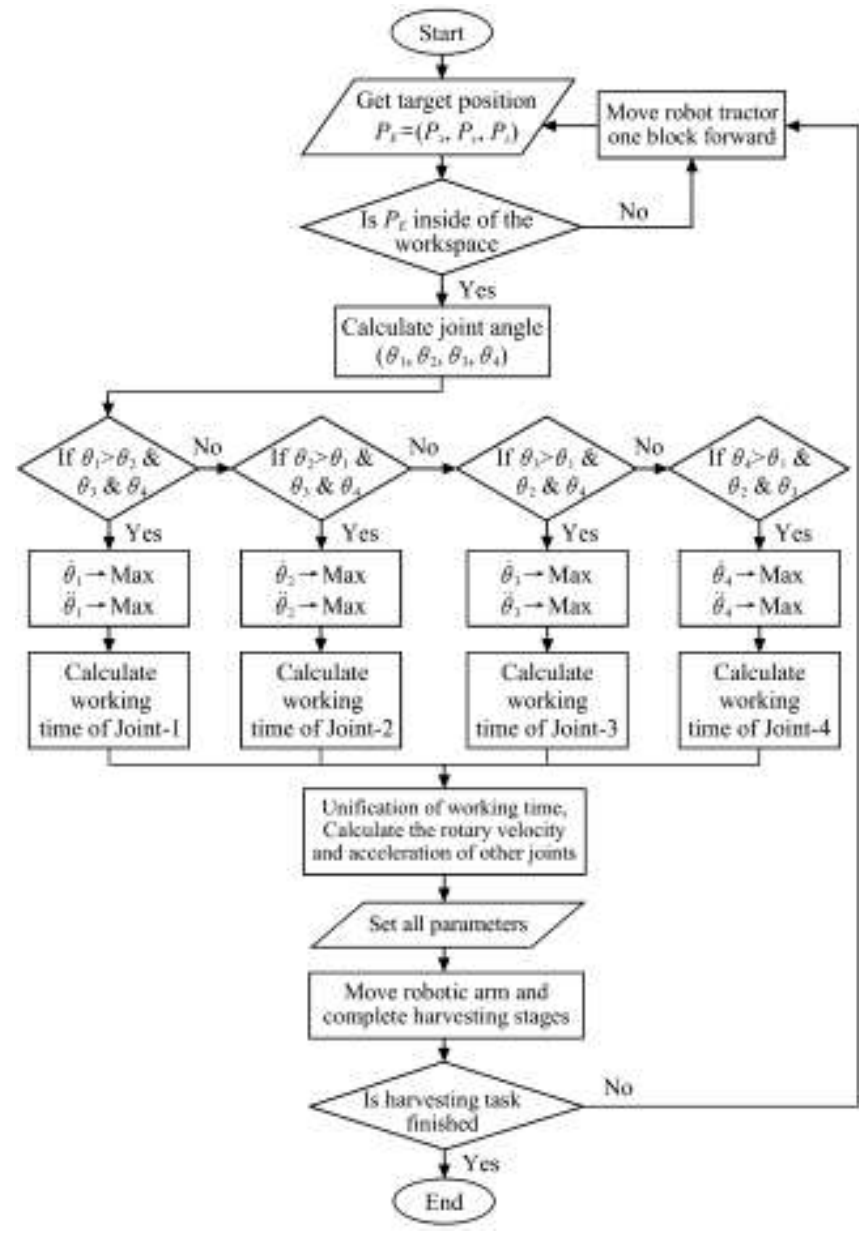

Figure 8 Controlling flowchart of system

analysis gave the velocity and acceleration of each joint using the calculated torque and physical properties of RAVeBots- 1 elements (e.g. link length, mass, the center of mass, and moment of inertia). The aim of this analysis was to determine the maximum velocity and acceleration values. This was necessary to assess and determined how to limit velocity and acceleration for optimized operation of each joint. Figure 9 indicates the dynamic analysis process of the RAVeBots-1. Unlike kinematics simulation, joint torque and gravity affect the physical behavior of a robotic arm in dynamic simulations. Based on $S=(\theta, \dot{\theta})$, the $\ddot{\theta}_{i}$, and torque $(\tau)$ as $\ddot{\theta}_{i}=d(s, \tau)$. The foundation $d$ was the forward dynamics of the robotic arm. In this calculation, $s$ is the supposed function of the two parameters $\theta_{i}$ (joint angle) and $\dot{\theta}_{i}$ (joint angular velocity). Moreover, joint angular acceleration $\left(\ddot{\theta}_{i}\right)$ represented the dynamic behavior of the system. The inverse dynamic analyzed the joints torque by using kinematic parameters, moment of inertia, and the specially designed algorithms. Results were applied to determine torque range and a suitable controlling signal. The inverse dynamics function $\left(d^{-1}\right)$, which must be adapted to the system in order to reach desired acceleration $\left(\tilde{\ddot{\theta}}_{i}\right)$, calculates the joint torques. The inverse dynamic was formulized as $\tau=d^{-1}\left(s, \tilde{\ddot{\theta}}_{i}\right)$.

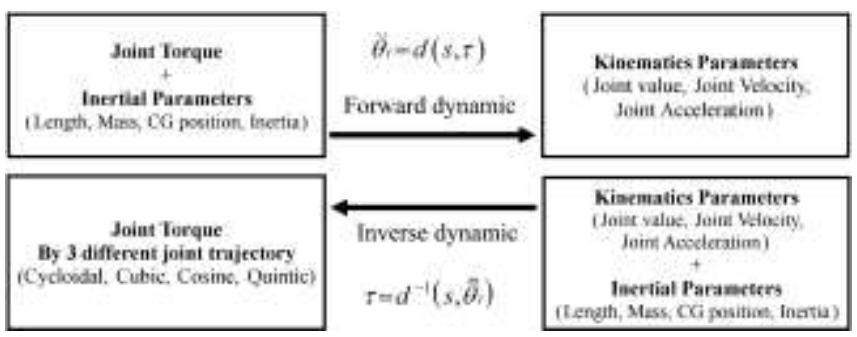

Figure 9 Dynamic analysis process

\subsection{Controlling methodology}

The robotic arm can maneuver between an infinite number of positions and paths inside the workspace. Sometimes, there are infinite trajectories to reach a particular point. Deciding between them by solving the $I K$ takes long calculation time. Such delay time is not acceptable for quick applications because the cycle time increase and the efficiency of designed system decrease. The cycle time is a period of time that a robotic harvesting system spends to harvest a target crop. The robot algorithm must select the best answer in the shortest possible time. In this regard, for grasping an object with a robotic arm, it is better to investigate an efficient methodology. In this study the arm was designed to harvest a heavy-weight crop, thus reviewing optimized harvesting methods could help to increase reaction speed and decrease the cycle time. After reviewing the various methods, an specific method was selected as an efficient way to harvest heavy crops which includes four steps: (1) grasping / picking the crop; (2) cutting the stem; (3) lifting; and (4) transportation (Figure 10). As a prerequisite of this method, the robotic arm must move from the transportation position to working position. The transportation position is a particular position in which all servo motors are set at

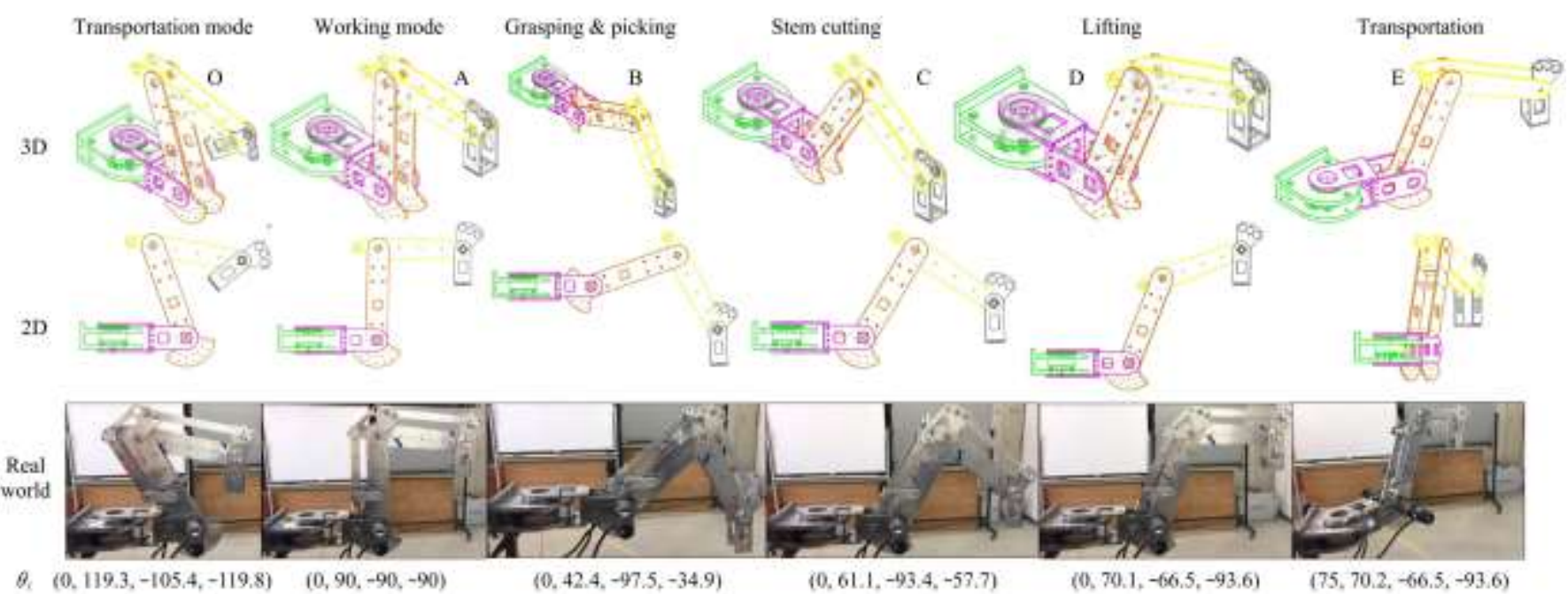

Figure 10 Harvesting stage and related parameters based on a developed algorithm 
the minimum angle. This position is defined for when the robot tractor finishes the harvesting task and it wants to transport out of the field. Based on the structure of robot, the $\theta_{1}, \theta_{2}, \theta_{3}$, and $\theta_{4}$ were chosen to be $0^{\circ}, 119.3^{\circ},-105^{\circ}$, and $-119.8^{\circ}$ as rest angles in the transportation position. During harvesting, the grasping position is chosen based on commands received from recognition-system regarding a crop's location. According to the physical properties of pumpkin, the stem-cutting stage must have a delay of 2-5 s. In this stage the robot has the opportunity to cut the crop's stem. The lifting and transportation stages are the essential steps that follow to carry the crops to the truck. As mentioned above, switching from the transportation to the working position must occur before the harvesting methodology starts. The working position was set as an initial point in the controlling system, and the recognition system assesses it as a start point. After harvesting, the program returns the robot to the transportation position when the operator decides to finish. This position is important because it protects the joints and structure against tractor vibration and oscillation during transportation.

\section{Results and discussion}

In this study, experiments and optimizations presented in (1) DOF and economic optimization, (2) PPW comparison with similar industrial robotic arms, (3) system reaction speed (to ensure sufficient accuracy to pass the determined trajectories in minimum time), (4) the accuracy and repeatability of system (based on the intended function and component parameters), (5) the designed harvesting methodology evaluation, and (6) the workspace (to ensure the system meets all needs).

\subsection{DOF selection and economic optimization}

To select an appropriated DOF for a robotic arm, it was needed to evaluate an invariant structure (with constant main parameters) in different conditions. It can help to design an optimized structure. In this section, the overall length of links ( $L=\sum_{i=0}^{n} L_{i}$ ), and the height of the installation position $(h)$ were considered constant (Figure 11). The $L$ and $h$ were considered $6 a$ and $1.5 a$, respectively. By considering the constant parameters, the other parameters such as the number of joints, type of joints and DOF were varied and the results were compared (Figure 12). In all conditions, the distance between installation location to $J_{1}\left(L_{1}\right)$ was considered $1.5 a$. The $a=20 \mathrm{~cm}$ was a unit length and all parameters were simplified based on this unit. The $a$ was chosen randomly and the ratios was set based on designed robotic arm parameters. The length of main link was chosen $6 a$ which divided equally to reach the desired $n$-DOF. After simulation, different parameters including $I_{v}, I_{s}, F A, H A$, $H L, V_{n}$, and $S_{n}$ were measured and compared (see abbreviations table). As shown in Figure 12, the workspace of 1-DOF and 2-DOF was zero because this DOF could move in a constant length in 2D and 3D space, respectively. The 3-DOF, 4-DOF, and 5-DOF have covered a certain workspace (green volume) and harvesting surface (brown area). As shown in Figure 13, the $I_{v}$, $H A_{\max },\left|H A_{\min }\right|$ and $H L$ was increased when the DOF increased from 3 to 5, but the $I_{s}, F A_{\max }, F A_{\min }$ almost remained constant. Based on the calculations, the minimum acceptable $H L$ has to be more than $4 a$. In the cases of 3-DOF, 4-DOF, and 5-DOF, the $S_{n}$ was calculated $41.36 a^{2}, 48.26 a^{2}$, and $49.65 a^{2}$, and the $H A$ was $3.2 a, 4.24 a$ and $4.5 a$, respectively. The $H A$ of $3-D O F$ was less than requirement. This parameter has no significantly different between 4-DOF and 5-DOF. Then the 4-DOF is the optimized value in physical point of view.

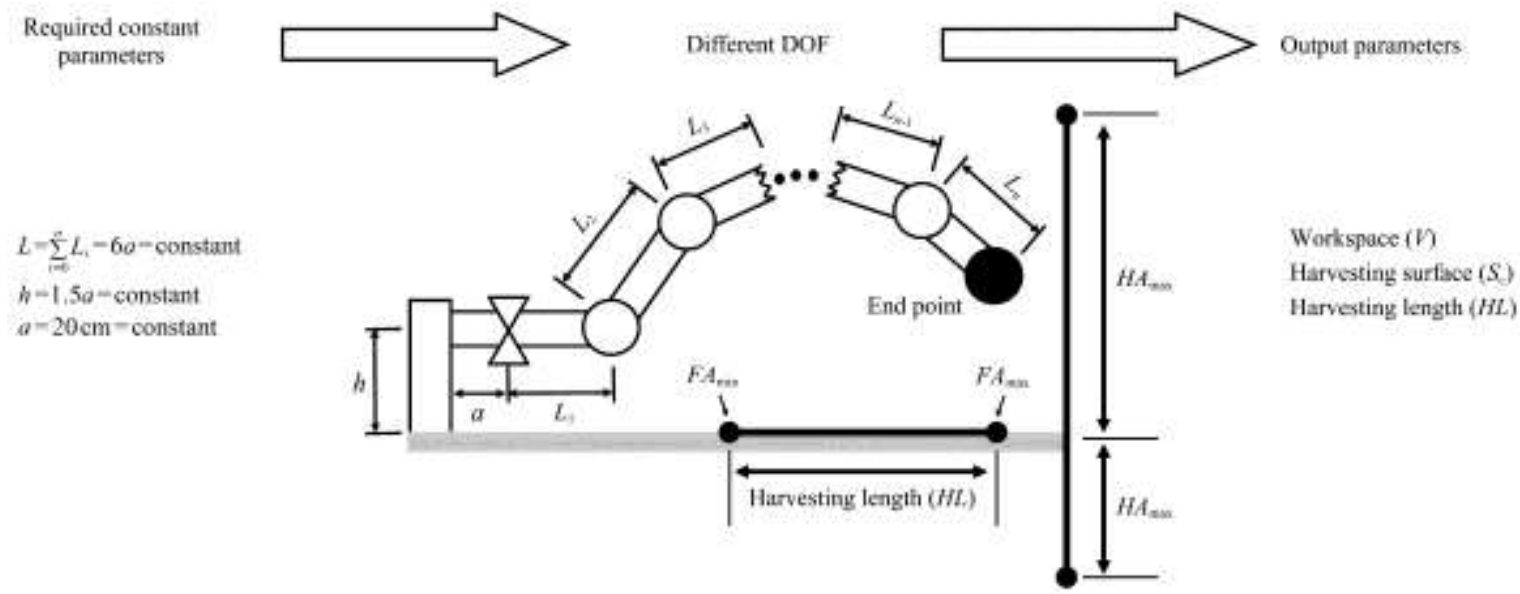

Figure 11 DOF optimization methodology

Diagram

Figure 12 Comparison of different DOF on the workspace 


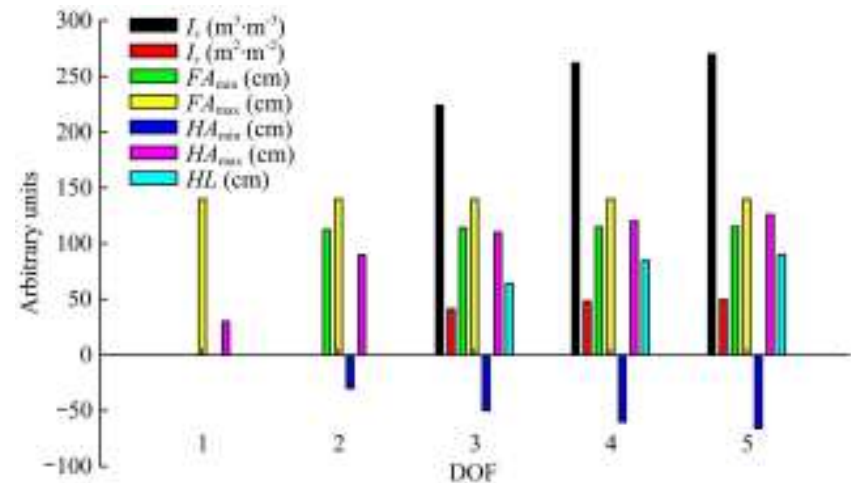

Figure 13 Required parameters in different DOF

In the next step, the economic aspects of different DOF were evaluated. Figure 14 indicates that the economic and energy evaluation of different DOFs. In this evaluation, different expense sources such as actuating cost, material cost, manufacturing expenses, mechanical parts, electronic component prices, and energy consumptions was considered. Each parameter was calculated based on Japanese market price and then the indexes (such as actuator index (price per $100000 ¥$ ), material index (price per $100000 ¥)$, manufacturing index (price per $100000 ¥$ ), mechanical index (price per $100000 ¥$ ), electronic index (price per $100000 ¥$ ), energy index (required power price per $100000 ¥)$ ) were measured and compared with the harvestable surface $\left(S_{n}\right)$ and $H L$. As the results indicated, each economic and energy index were increased by the DOF growth. When the DOF increase, the number of required actuator (servo motor), amplifier, connection cables, joint components, controlling components, and manufacturing time are also increase. More servo motor required more energy and connection cable, $\mathrm{q}$ and, the controlling algorithm gets more complicated. But, increasing the DOF from 4 to 5, didn't increase the $I_{s}$ and $H L$ significantly. Then 5-DOF robotic cannot be an optimized structure to described application and required parameters. As a conclusion, by consideration a constant length and different DOF, a 4-DOF could be an adequate structure which can support a maximum $V_{n}$ and $S_{n}$, at a minimum cost. Based on these evaluations, a 4-DOF structure was selected to develop a harvesting robotic system.

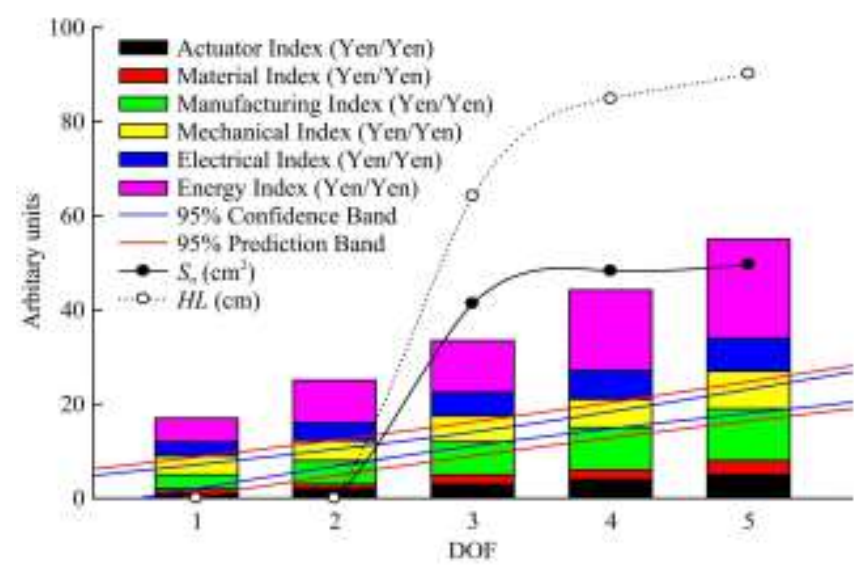

Figure 14 Economic optimization indexes

\subsection{PPW comparison}

To design of a mobile robot, the weight of the robotic arm and its payload are important parameters. As a combination of a robotic arm with a robot tractor was the aim of this study, a maximum payload ration with a minimum weight of robotic arm (maximum PPW) was required. Figure 15 indicates the PPW of different industrial robots which has a payload within the desired range $(15-30 \mathrm{~kg})$. Several industrial robots from different companies which have a payload in the required range such as FANUC $^{[55]}$ Motoman ${ }^{[56]}, \mathrm{ABB}^{[57]}$, Denso $^{[58]}$, Comau ${ }^{[59]}$, Kawasaki $^{[60]}$, and OTC Daihen ${ }^{[61]}$ was studied. The PPW of each was measured by using the datasheet. The average PPW of all robotic arms was almost 0.085 which means a robotic arm with $8.5 \mathrm{~kg}$ payload and $100 \mathrm{~kg}$ weight. The average weight of a ripe pumpkin is $3 \mathrm{~kg}$ which can reach to $10 \mathrm{~kg}^{[41]}$. By consideration of $\mathrm{FOS}=2$, the minimum PPW must be more than 0.2 , when the weight of the robotic arm is $100 \mathrm{~kg}$. As shown in Figure 15, the PPW of all the evaluated robotic arm was less than 0.2, except FANUC, LR Mate 200iD (PPW=0.28), and Denso, VS-6577 $(\mathrm{PPW} \approx 0.2)$ models which have a heavy weight and small workspace for described application, respectively. Based on these results, this robotic arm cannot provide the required parameters (mentioned in section 0). Also, the maximum front balance weight of the used robot tractor (Table 2) was $150 \mathrm{~kg}$ which is smaller than the weight of mentioned industrial robotic arm. Based on the final experimentation of designed robotic arm (RAVeBots-1), its maximum PPW is 0.21 (Table 1) which not only is more than average PPW of all robotic arms but also is more than the required range to harvest heavy-weight crops. Based on the mentioned reasons, the RAVeBots-1 with high PPW, and an appropriated payload $(25 \mathrm{~kg})$ was meet all needed required parameters to harvest heavy-weight crops.

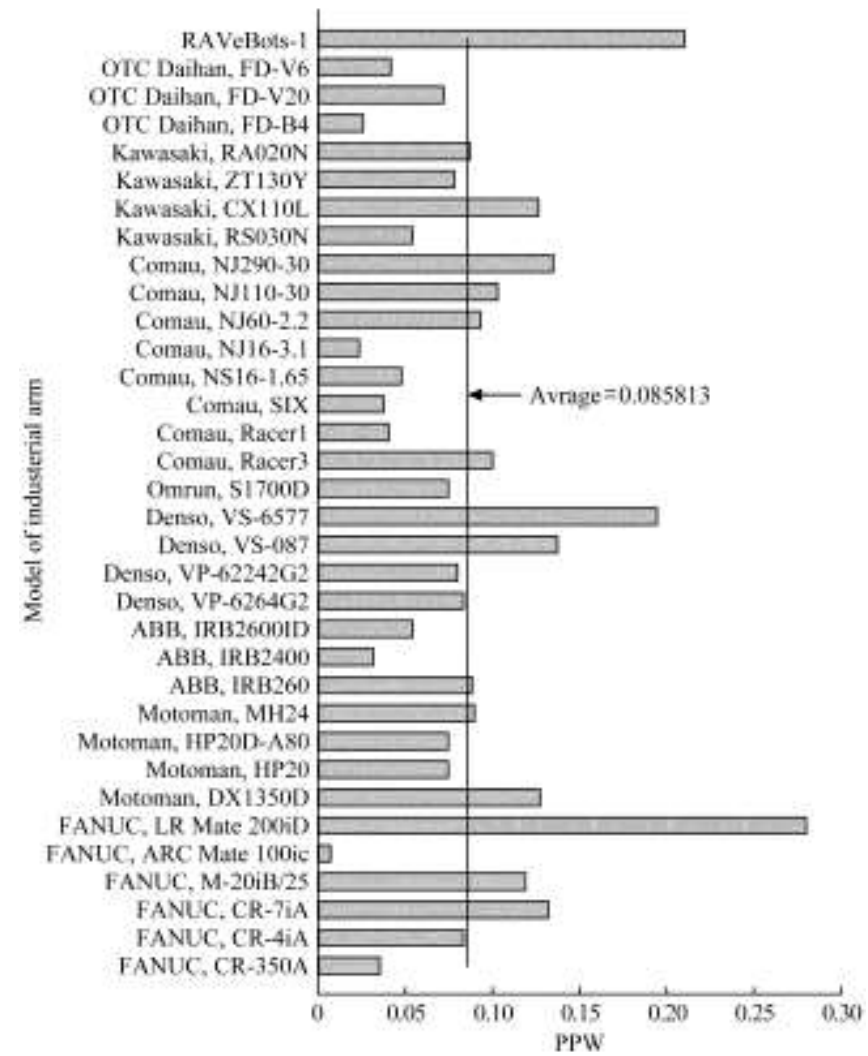

Figure 15 PPW comparison

\subsection{Joint velocity}

In this section, the analytical output of joint speed and torque with the experimental output were compared. According to the coding commands and datasheet of servo motors, the speed of all servo motors must follow the specified equation, $V=V_{0}+a^{0.5}\left(T-T_{o} / b\right)^{2} . \quad$ In the equation, $a$ and $b$ are the constant values of the designed algorithm determined at each time-step. The rotary motion has to start with an acceleration and stop with a 
deceleration. This acceleration and deceleration can reduce the torque, inertia, vibration and it can provide a smooth maneuver path. Figure 16 indicated the comparison of experimental output with analysis results. The behavior of this change was steady for all joints at each functional step. As shown in Table 3 and Table 4 , there was no significant difference between values for real-world experimental results $(M=3.03, S D=1.73)$ and analysis results $(M=3.04, S D=1.7) ; t(-7.42)=8099, p=0.064$. This indicated that the values of force, link length, and other related parameters were constant in the same situation. It can be concluded that torque change in the real-world experiments was not significantly different from the analytical result, however, the effect of the actual fields condition such as vibration, on the mentioned parameter will be evaluated.

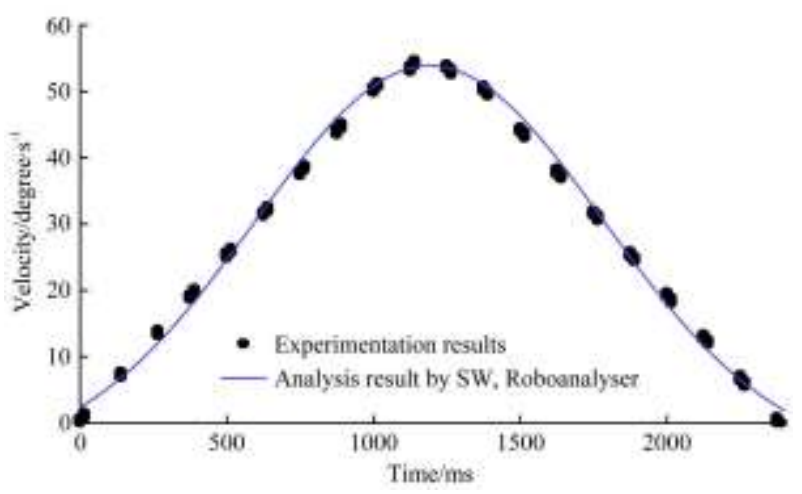

Figure 16 Joints velocity behavior based on analysis and real-world experimentation

Table 3 Paired samples statistics

\begin{tabular}{ccccc}
\hline & Mean & N & Std. deviation \\
\hline \multirow{2}{*}{ Pair 1 } & Experiments & 3.03 & 8100 & 1.73 \\
& Analysis & 3.04 & 8100 & 1.69 \\
\hline
\end{tabular}

Table 4 Completion of experimentation result of paired samples $t$-Test

\begin{tabular}{|c|c|c|c|c|c|c|c|c|}
\hline & \multirow{2}{*}{ Mean } & \multirow{2}{*}{ Std. deviation } & \multirow{2}{*}{ Std. error mean } & \multicolumn{2}{|c|}{$95 \%$ confidence interval of the difference } & \multirow{2}{*}{$t$} & \multirow{2}{*}{ df } & \multirow{2}{*}{ Sig. (2-tailed) } \\
\hline & & & & Lower & Upper & & & \\
\hline Experiments - Analysis & -0.015 & 0.185 & 0.00207 & -0.019 & -0.011 & -7.418 & 8099 & 0.064 \\
\hline
\end{tabular}

\subsection{Calibration}

Before using the developed robotic arm, it is necessary to calibrate the motion. Such calibration must involve combining experimental values for end-effector position in space with algorithm standard expected values. Calibration of the system was conducted for four missions, including circular, rectangular, square, and triangular missions (Figure 17). It was assumed that the motions had to follow a point-to-point (PTP) motion with variable velocity and a linear trajectory is not a priority in this motion. Calibration results showed that the average error of the system in different motions was $2.2 \mathrm{~mm}$ in $X$-direction, $2.11 \mathrm{~mm}$ in $Y$-direction and $1.24 \mathrm{~mm}$ in Z-direction. The average resultant positional accuracy of designed robotic arm was $1.85 \mathrm{~mm}$. The maximum and minimum accuracy in $X$ and $Y$-direction $\left(\right.$ error $_{x}$, error $_{y}$ ) were found with the rectangular motion $(2.42 \mathrm{~mm}, \quad 2.55 \mathrm{~mm})$ and circular motion $(1.66 \mathrm{~mm}, 1.24 \mathrm{~mm})$, respectively (Table 5). But in the $Z$-direction, the maximum and minimum accuracy was found with square motion $(2.74 \mathrm{~mm})$ and triangular motion $(0.49 \mathrm{~mm})$, respectively. In the rectangular motion, the algorithm adhered to linear motion, but torque optimization necessitated non-linear motion. In contrast, a special step was developed in the algorithm to drive the system in a

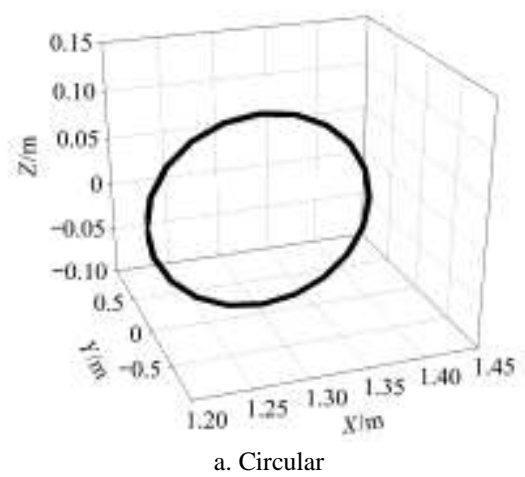

circular motion and curves. The results showed that the accuracy of different missions has no significantly different. The PTP motion (which used in rectangular, square, and triangular motions) was less accurate than linear motion (which used in a circular motion). It should be noted that the PTP motion spends a short time to finish a mission in comparing by a linear motion. It is recommended to use linear motion and PTP motion for high accuracy and high-speed applications, respectively. The calculation results indicated that the repeatability of each mission (circular $( \pm 0.62 \mathrm{~mm})$, rectangular $( \pm 0.59 \mathrm{~mm})$, square $( \pm 0.62 \mathrm{~mm})$, and triangular $( \pm 0.21 \mathrm{~mm})$ ) are not significantly different. The average reparability of the system was calculated $\pm 0.51 \mathrm{~mm}$. Also, the results demonstrated that the average system error was suitable for the defined application, and the robotic arm had sufficient accuracy to harvest a heavy-weight crop. Over short distances, the error could be reduced to $1 \mathrm{~mm}$ due to algorithm behavior. This indicates that the robotic arm has the capacity to maneuver in accurate missions. As these experiments were done in laboratory condition, the same tests will be repeated in real field condition to find the effect of vibration on performance in the future study. It is expected that the parameters of the real field increase the values of accuracy and repeatability.

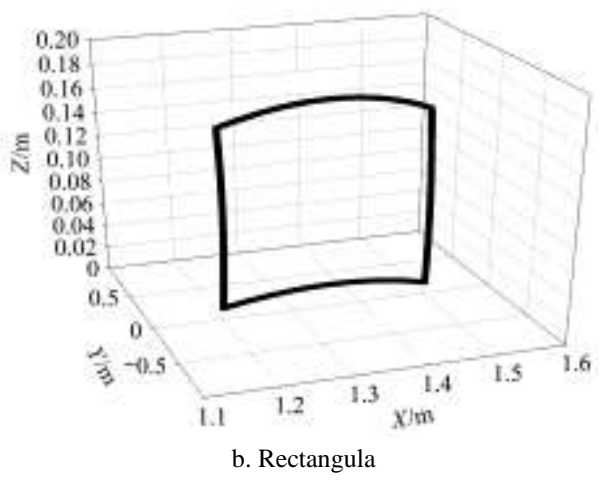



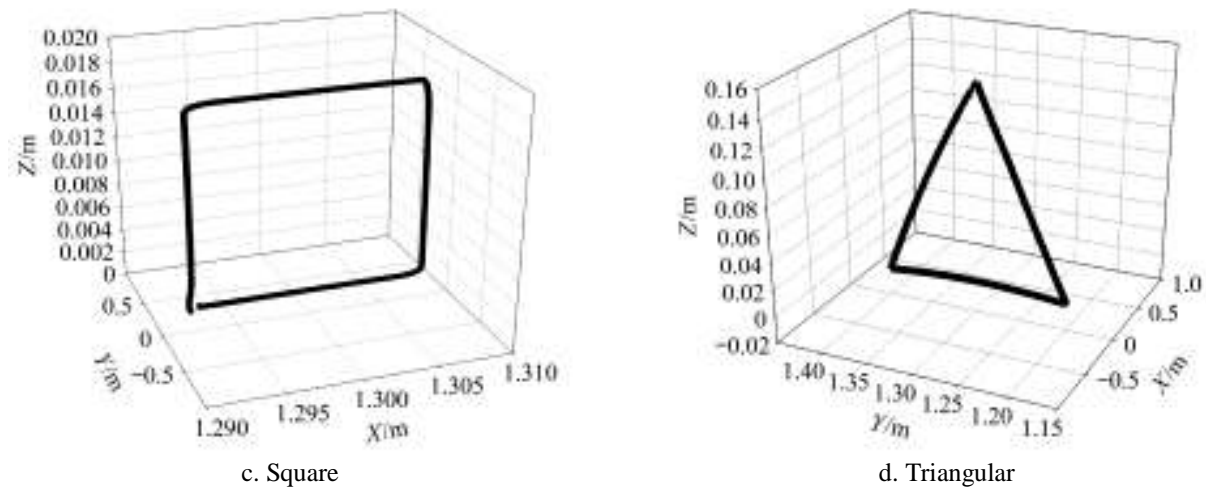

Figure 17 PTP motions calibration resuls

Table 5 PTP motion error

\begin{tabular}{ccccccc}
\hline & Circular & Rectangular & Square & Triangular & Average \\
\hline & $X$-direction & 1.66 & 2.42 & 2.31 & 2.4 & 2.2 \\
Accuracy & $Y$-direction & 1.24 & 2.55 & 2.37 & 2.28 & 2.11 \\
$A_{p} / \mathrm{mm}$ & $Z$-direction & 0.25 & 1.51 & 2.72 & 0.49 & 1.24 \\
& Resultant & 1.05 & 2.16 & 2.47 & 1.72 & 1.85 \\
\hline \multicolumn{2}{l}{ Repeatability, $R_{p} / \mathrm{mm}$} & \pm 0.62 & \pm 0.59 & \pm 0.62 & \pm 0.21 & \pm 0.51 \\
\hline
\end{tabular}

\subsection{Harvesting methodology}

As mentioned in section 2.3, an optimized methodology can increase harvesting speed and decrease cycle time by eliminating unnecessary motions. Here, a controlling methodology was determined, as shown in Figure 10. In Figure 18, robot motion begins from the transportation position. It moves through the working position, grasping position, stem-cutting position, and then begins to carry the object (crop) to the truck. This methodology was accomplished in the analysis environment using Solidworks software, and in real-world experiments, as shown in Figure 19. These tests were done when a constant $25 \mathrm{~kg}$ weight (no end-effector or different pumpkins with various weight) was applied on. The results of analysis in the $X, Y$ and $Z$ directions had no significant difference with real-world experimental as shown in Table 6. Average standard deviation in the $X, Y$ and $Z$ directions was $3.78 \mathrm{~mm}, 3.81 \mathrm{~mm}$, and $3.91 \mathrm{~mm}$, respectively. Thus, accuracy and authenticity of the controlling program were shown to be quite high. This test will be repeated when the end-effector installed on the robotic $\operatorname{arm}^{[46]}$ and also when different pumpkins by diverse weight are harvested in future studies.

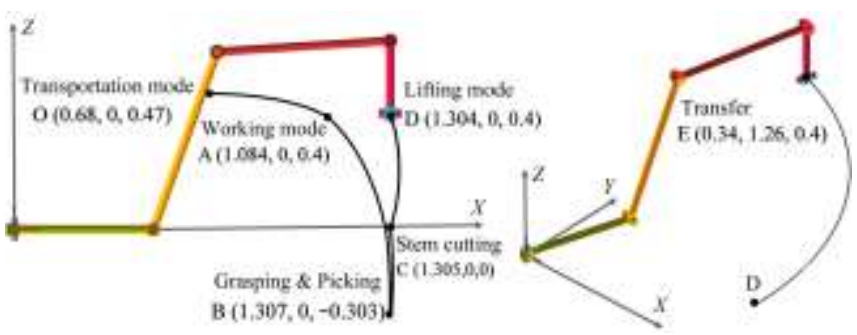

Figure 18 Endpoint position movement methodology

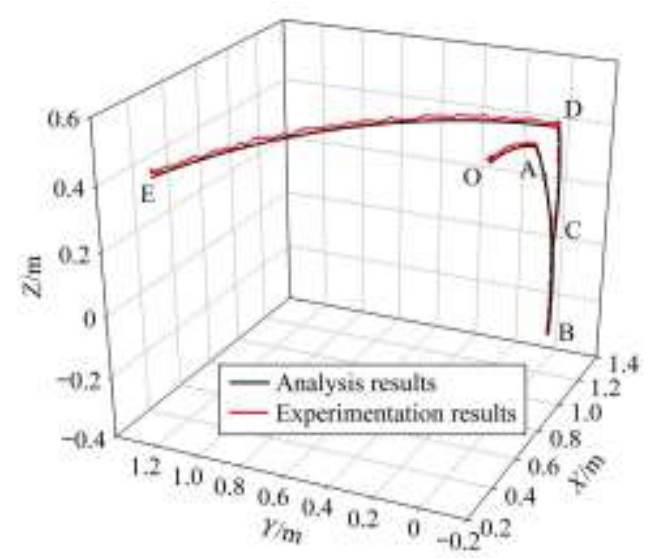

Figure 19 Endpoint position in 3D space

Table 6 Statistical result of path compression

\begin{tabular}{|c|c|c|c|c|c|c|c|c|c|}
\hline & & \multirow{2}{*}{ Mean/mm } & \multirow{2}{*}{ Std. deviation/mm } & \multirow{2}{*}{$\begin{array}{l}\text { Std. Error } \\
\text { Mean }\end{array}$} & \multicolumn{2}{|c|}{$95 \%$ confidence interval of the difference } & \multirow{2}{*}{$\mathrm{t}$} & \multirow{2}{*}{ df } & \multirow{2}{*}{ Sig. (2-tailed) } \\
\hline & & & & & Lower & Upper & & & \\
\hline Pair 1 & $X_{\text {analysis }}-X_{\text {exp }}$ & -5.82 & 3.78 & 0.169 & -6.16 & -5.49 & -34.46 & 500 & 0.076 \\
\hline Pair 2 & $Y_{\text {analysis }}-Y_{\exp }$ & -6.15 & 3.81 & 0.170 & -6.49 & -5.82 & -36.10 & 500 & 0.055 \\
\hline Pair 3 & $Z_{\text {analysis }}-Z_{\text {exp }}$ & -6.09 & 3.91 & 0.174 & -6.44 & -5.75 & -34.86 & 500 & 0.092 \\
\hline
\end{tabular}

As the final result indicates, it was necessary to assess velocity and torque behavior in the course of the methodology from point $O$ to $E$. As shown in Figure 20, velocity ranged between $-96.14 \%$ and $110.55 \%$. The velocity was changeable based on the described programming parameters and the experimental results were in good accord. The torque behavior was not predictable due to the different parameters indicated in a nonspecific pattern. Assuming $F O S=2$ in these results, the maximum torque of $J_{1}, J_{2}, J_{3}$ and $J_{4}$ was $143.75 \mathrm{~N} \cdot \mathrm{m}, 530.78 \mathrm{~N} \cdot \mathrm{m}, 242.81 \mathrm{~N} \cdot \mathrm{m}$, and $24.68 \mathrm{~N} \cdot \mathrm{m}$, respectively. This means that the torque value $J_{1}, J_{2}, J_{3}$ and $J_{4}$ were $71.87 \mathrm{~N} \cdot \mathrm{m}, 265.4 \mathrm{~N} \cdot \mathrm{m}, 121.4 \mathrm{~N} \cdot \mathrm{m}$, and $12.34 \mathrm{~N} \cdot \mathrm{m}$, respectively. These values are in the standard range of applied servo motor mentioned in datasheet. It is expected that the main parameter such as torque can have turbulent due to big inertia when the robot carries an object with various heavy weight, but the system designed to control torque by controlling the rotary velocity of joints, acceleration and deceleration in each servo motor.

\subsection{Working space}

After finding the optimized DOF, the structure of robotic arm was designed. The robotic arm had designed with a $F A, H L$, and $V_{n}$ of $1.83 \mathrm{~mm}, 1.43 \mathrm{~m}$, and $17.25 \mathrm{~m}^{3}$, respectively as shown Figure 21a. After manufacturing, different limitations including manufacturing errors, joint limitations, and components interferences had reduced the required parameter (from designed system). After several improvements, the $F A, H L$, and $V_{n}$ of final 
system resulted as $2.024 \mathrm{~m}, 1.36 \mathrm{~m}$, and $8.27 \mathrm{~m}^{3}$, respectively, as shown in Figure 21d. The $S_{c, \max }$ of final RAVeBots-1 was reached to $3.52 \mathrm{~m}^{2}$ which only refers to the designed robotic arm mounted on the robot tractor without any end effector (Figures 21c

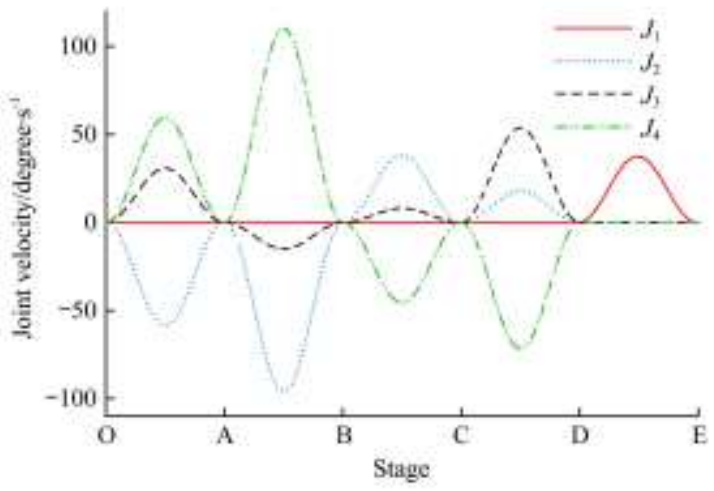

a. Joints velocity and 21d). After installation of end-effector, the $F A, H L, S_{c \text {,max }}$ and $V_{n}$ were increased to $2.93 \mathrm{~mm}, 1.48 \mathrm{~m}, 6.37 \mathrm{~m}^{2}$ and $12.06 \mathrm{~m}^{3}$, respectively. These values met the requirements and the system cam harvest the target crops properly.

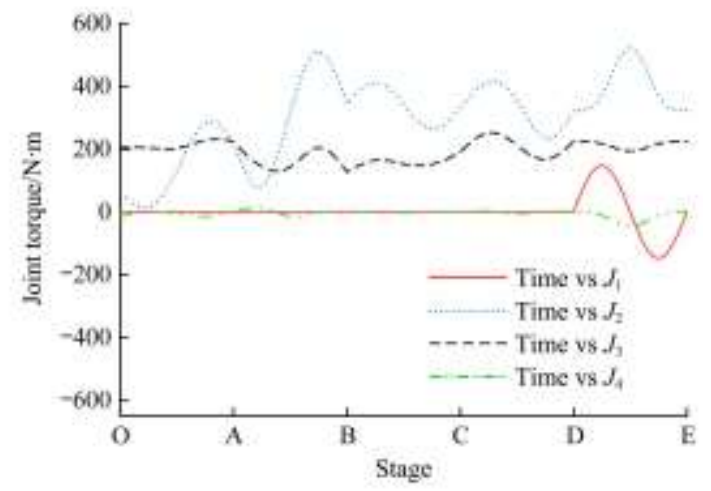

b. Joints torque

Figure 20 Analysis results of joints velocity and joints torque
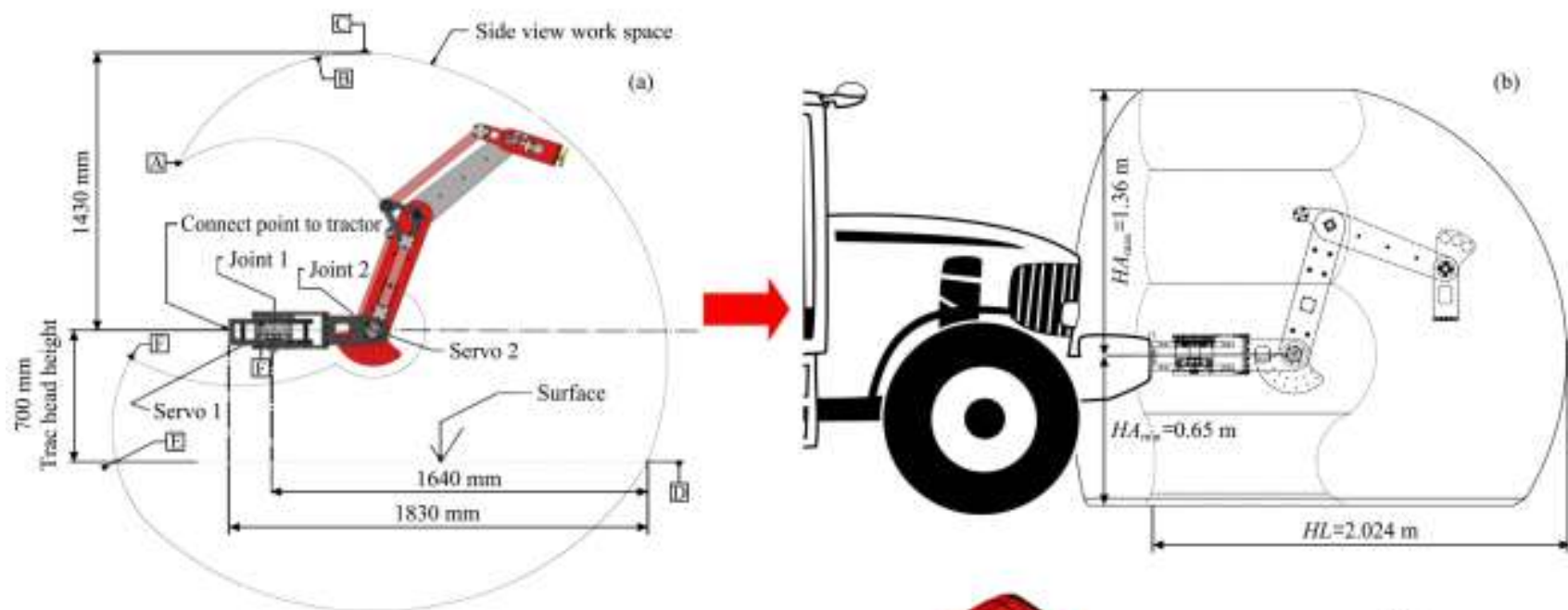

(c)

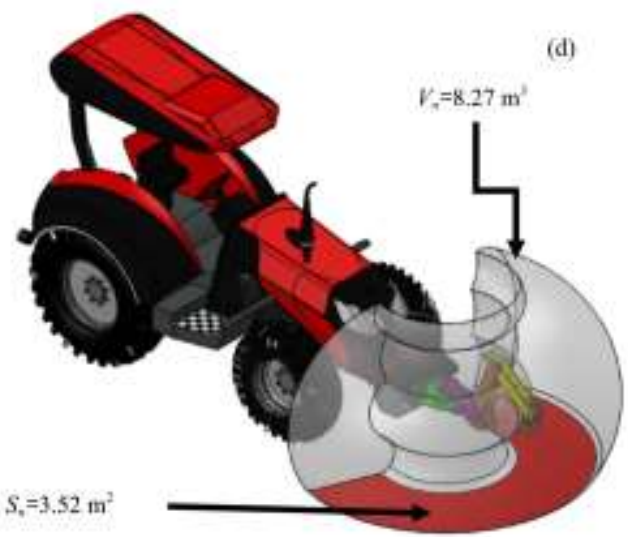

Figure 21 (a) The parameters of designed robotic arm, (b) the parameters of manufactured robotic arm (c), covered surface of final system before end-effector installation, (d) a 3D illustration of final system before end-effector installation

\section{Conclusions}

In this study, the development procedure of a robotic arm for heavy duty application was presented. The main idea was developing an actuating unit and install on robot tractor to harvest pumpkin, watermelon, and melon which are known as a heavy-weight crop.

In this regard, firstly, a standard manufacturing process was selected, and the platform was designed by using Solidworks software. After evaluation of different economic and technical indexes, a 5-DOF (4-DOF for robotic arm + 1-DOF for end-effector) mechanism with revolute joints was found as a proper DOF to design the platform of the robotic arm. The robotic arm was designed for a payload of $25 \mathrm{~kg}$ because the pumpkins' weight can reach up $10 \mathrm{~kg}$, and FOS of 2 because the real field condition is not predictable. To reduce the weight of the structure, mainly aluminum (AL5052) used to manufacture most of the components. The PPW evaluation indicated that the average PPW of current industrial robotic arms (which meet the requirements) and RAVeBots- 1 were 0.085 and 0.21 , respectively.

Secondly, the controlling unit based on PLC system and the controlling algorithm by using D-H method was developed. The 
controlling unit consisted of a PC, position board, amplifiers, power supply, and brake control unit which could control five servo motors of each join. The controlling algorithm was designed by consideration on kinematic and dynamic points of view. To optimize and simplify the controlling algorithm, a specific methodology was developed which contained four steps as (1) grasping / picking the crop; (2) cutting the stem; (3) lifting; and (4) transportation. After development, the robotic arm had installed on a robot tractor (EG453) and the performance system statically and dynamically was evaluated.

Thirdly, the accuracy and repeatability of the developed system were measured in four missions when a $25 \mathrm{~kg}$ weight was applied on the endpoint. The results indicated that the system averagely had a resultant accuracy of $1.05 \mathrm{~mm}, 2.06 \mathrm{~mm}, 2.04 \mathrm{~mm}$, and $1.72 \mathrm{~mm}$ in circular, rectangular, square, and triangular missions. The average repeatability of all missions was $\pm 0.51 \mathrm{~mm}$.

Finally, the physical specifications of the developed system were measured. The results indicated that the developed system (without end-effector) could present a front access $(F A)$, harvesting length $(H L)$, and workspace volume $\left(V_{n}\right)$ of $2.024 \mathrm{~m}, 1.36 \mathrm{~m}$, and $8.27 \mathrm{~m}^{3}$, respectively. After end-effector installation, the $F A, H L$, and $V_{n}$ were increased to $2.93 \mathrm{~mm}, 1.48 \mathrm{~m}$, and $12.06 \mathrm{~m}^{3}$, respectively. The final specifications of the system indicated the at the design robot meet the requirements and it is capable to harvest pumpkins properly.

Hopefully, the RAVebots-1 will be utilized in everyday agricultural practices, especially in the harvest of heavy-weight crops. This agricultural robot is capable to collect physical properties of crops (weight, volume, density, etc.) as well as harvesting task. It is also able to do the watering, seeding, fertilizing, and weeding tasks as an intelligent agricultural robot.

\section{Acknowledgment}

This study was supported by the Cross-ministerial Strategic Innovation Promotion Program (SIP) managed by Cabinet Office. Our warmest appreciation goes to Dr. Kazunobu Ishii (Associated professor, Hokkaido University), and Dr. Hiroshi Okamoto (Assistant professor, Hokkaido University), for their insightful assistance.

\section{Nomenclature and abbreviation}

\begin{tabular}{clc}
\hline \multicolumn{1}{c}{ Parameter } & \multicolumn{1}{c}{ Description } & Unit \\
\hline$A_{p i}$ & Positional accuracy in $i$-direction & $\mathrm{mm}$ \\
$\bar{x}$ & Average x-value of attained position & $\mathrm{mm}$ \\
$x_{c}$ & Commanded position in the $x$-axis & $\mathrm{mm}$ \\
$\bar{y}$ & Average $y$-value of attained position & $\mathrm{mm}$ \\
$y_{c}$ & Commanded position in the $y$-axis & $\mathrm{mm}$ \\
$\bar{z}$ & Average $z$-value of attained position & $\mathrm{mm}$ \\
$z_{c}$ & Commanded position in the $z$-axis & $\mathrm{mm}$ \\
$x_{r}$ & Attained position in the $x$-direction & $\mathrm{mm}$ \\
$y_{r}$ & Attained position in the $y$-direction & $\mathrm{mm}$ \\
$z_{r}$ & Attained position in the $z$-direction & $\mathrm{mm}$ \\
$F A$ & Front access & $\mathrm{m}$ \\
$H A$ & Height access & $\mathrm{m}$ \\
$H L$ & Harvesting length & $\mathrm{m}$ \\
$V_{n}$ & Workspace volume & $\mathrm{m}$ \\
$S_{n}$ & Harvestable surface & $\mathrm{m}$ \\
$P_{E}$ & Desired target position & $\mathrm{m}$ \\
\hline & &
\end{tabular}

\begin{tabular}{|c|c|c|}
\hline Parameter & Description & Unit \\
\hline$L_{i}$ & Length of link number $i$ & $\mathrm{~m}$ \\
\hline$I_{v}$ & Workspace index $\left(V_{n} / a^{3}\right)$ & $\mathrm{m}^{3} \cdot \mathrm{m}^{-3}$ \\
\hline$I_{s}$ & Harvesting surface index $\left(S_{n} / a^{2}\right)$ & $\mathrm{m}^{2} \cdot \mathrm{m}^{-2}$ \\
\hline$T$ & Time & $\mathrm{s}$ \\
\hline$T_{0}$ & Start time & $\mathrm{s}$ \\
\hline$V$ & Normal velocity of servo motor & $\left({ }^{\circ}\right) \cdot \mathrm{s}^{-1}$ \\
\hline$V_{0}$ & Velocity of servo motor at the start point & $\left({ }^{\circ}\right) \cdot \mathrm{s}^{-1}$ \\
\hline$\theta_{i}$ & Joint angle & $\left({ }^{\circ}\right)$ \\
\hline$\dot{\theta}_{i}$ & Angular velocity of joint & $\left({ }^{\circ}\right) \cdot \mathrm{s}^{-1}$ \\
\hline$\ddot{\theta}_{i}$ & Angular acceleration of joint & $\left({ }^{\circ}\right) \cdot \mathrm{s}^{-2}$ \\
\hline$\tau$ & Torque & $\mathrm{N} \cdot \mathrm{m}$ \\
\hline$n_{1}$ & Number of attained points in each mission & - \\
\hline$n_{2}$ & Number of repetition & - \\
\hline$a, b$ & Constant values & - \\
\hline$J_{i}$ & Joint number $\underline{\mathrm{i}}$ & - \\
\hline $\mathrm{HBH}$ & Human-based harvesting & - \\
\hline HLH & Human-led harvesting & - \\
\hline RAVeBots-1 & Robotic arm for vehicle robotics-first generation & - \\
\hline FOS & Factor of Safety & - \\
\hline PTP & Point-to-point motion & - \\
\hline FK & Forward kinematics & - \\
\hline IK & Inverse kinematics & - \\
\hline OPF & Operational functions & - \\
\hline APF & Application functions & - \\
\hline AXF & Auxiliary functions & - \\
\hline TCM & Torque control mode & - \\
\hline SCM & Speed control mode & - \\
\hline PCM & Position control mode & - \\
\hline D-H & Denevit-Hartenberg method & - \\
\hline
\end{tabular}

\section{[References]}

[1] Statistical handbook of Japan 2015: Statistics Bureau Ministry of Internal Affairs and Communications Japan; 2015.

[2] USDA. Farm Demographics - U.S. Farmers by Gender, Age, Race, Ethnicity, and More. www.agcensus.usda.gov. Accessed on [2018-05-31]

[3] Asadollahpour A, Omidinajafabadi M, Jamalhosseini S. Factors affecting the conversion to organic farming in Iran: A case study of mazandaran rice producers. Science International (Lahore), 2014; 26(4): 1844-1860.

[4] Ellen L, William C, Erica S, Keith F. Global agricultural productivity report http://www.globalharvestinitiative.org/GAP/2013_GAP_Report_ BOOK_ONLINE.pdf. 2013 Accessed on [2018-0-31]

[5] Cassinis R, Tampalini F. AMIRoLoS an active marker internet-based robot localization system. Robotics and autonomous systems, 2007; 55(4) 306-315.

[6] Zion B, Mann M, Levin D, Shilo A, Rubinstein D, Shmulevich I. Harvest-order planning for a multiarm robotic harvester. Computers and Electronics in Agriculture, 2014; 103: 75-81.

[7] Hayashi S, Shigematsu K, Yamamoto S, Kobayashi K, Kohno Y, Kamata J, et al. Evaluation of a strawberry-harvesting robot in a field test. Biosystems Engineering, 2010; 105(2): 160-171.

[8] Feng Q C, Cheng W, Zhou J J, Wang X.. Design of structured-light vision system for tomato harvesting robot. Int J Agric \& Biol Eng, 2014; 7(2): 19-26.

[9] Feng Q C, Wang X, Zheng W G, Quan Q, Kai J. A new strawberry harvesting robot for elevated-trough culture. Int J Agric \& Biol Eng, 2012; 5(2): 1-8.

[10] De-An Z, Jidong L, Wei J, Ying Z, Yu C. Design and control of an apple harvesting robot. Biosystems Engineering, 2011; 110(2): 112-122.

[11] Barawid Jr OC, Mizushima A, Ishii K, Noguchi N. Development of an 
autonomous navigation system using a two-dimensional laser scanner in an orchard application. Biosystems Engineering, 2007; 96(2): 139-149.

[12] Tanigaki K, Fujiura T, Akase A, Imagawa J. Cherry-harvesting robot. Computers and Electronics in Agriculture, 2008; 63(1): 65-72.

[13] Kondo N, Monta M, Fujiura T. Fruit harvesting robots in Japan. Advances in Space Research, 1996; 18(1-2): 181-184.

[14] Zhang L B, Wang Y, Yang Q H, Bao G J, Gao F, Xun Y. Kinematics and trajectory planning of a cucumber harvesting robot manipulator. Int $\mathrm{J}$ Agric \& Biol Eng, 2009; 2(1): 1-7.

[15] Wang L L, Zhao B, Fan J W, Hu X A, Wei S, Li Y S, et al. Development of a tomato harvesting robot used in greenhouse. Int J Agric \& Biol Eng, 2017; 10(4): 140-149.

[16] Fu L S, Wang B, Cui Y J, Su S, Gejima Y, Kobayashi T. Kiwifruit recognition at nighttime using artificial lighting based on machine vision. Int J Agric \& Biol Eng, 2015; 8(4): 52-59.

[17] Tanner H G, Kyriakopoulos K J, Krikelis N I. Advanced agricultural robots: kinematics and dynamics of multiple mobile manipulators handling non-rigid material. Computers and Electronics in Agriculture, 2001; 31(1): 91-105.

[18] Toyama S, Yamamoto G. Development of wearable-agri-robot -mechanism for agricultural work. 2009 IEEE/RSJ International Conference on Intelligent Robots and Systems; Louis, USA2009, pp.5801-5806.

[19] Noguchi N, Barawid Jr O C. Robot farming system using multiple robot tractors in Japan agriculture. IFAC Proceedings Volumes, 2011; 44(1): 633-637.

[20] Zhang C, Yang L, Noguchi N. Development of a robot tractor controlled by a human-driven tractor system. Engineering in Agriculture, Environment and Food, 2015; 8(1): 7-12.

[21] Baeten J, Donné K, Boedrij S, Beckers W, Claesen E. Autonomous fruit picking machine: A robotic apple harvester. Field and Service Robotics: Results of the 6th International Conference. Berlin, Heidelberg: Springer Berlin Heidelberg, 2008; pp.531-539.

[22] Sites P W, Delwiche M J. Computer vision to locate fruit on a tree. ASAE, 1988; 31(1): 257-263.

[23] Sarig Y. Robotics of Fruit Harvesting: A state-of-the-art review. Journal of Agricultural Engineering Research, 1993; 54(4): 265-280.

[24] Lee B S, Rosa U A. Development of a canopy volume reduction technique for easy assessment and harvesting of valencia citrus fruits. ASAE, 2006; 49(6): 1695-1703.

[25] Plá F, Juste F, Ferri F. Feature extraction of spherical objects in image analysis: an application to robotic citrus harvesting. Computers and Electronics in Agriculture, 1993; 8(1): 57-72.

[26] Roy H. Economic analysis of robotic citrus harvesting in Florida. American Society of Agricultural Engineers, 1987; 30(2): 298.

[27] Hayashi S, Saito S, Iwasaki Y, Yamamoto S, Nagoya T, Kano K. Development of circulating-type movable bench system for strawberry cultivation. Japan Agricultural Research Quarterly: JARQ, 2011; 45(3): 285-293

[28] Kondo N, Nishitsuji Y, Ling P P, Ting K C. Visual feedback guided robotic cherry tomato harvesting, ASABE, 1996; 39(6): 2331-2338.

[29] Bac C W, van Henten E J, Hemming J, Edan Y. Harvesting robots for high-value crops: state-of-the-art review and challenges ahead. Journal of Field Robotics, 2014; 31(6): 888-911.

[30] Arndt G, Rudziejewski R, Stewart V A. On the future of automated selective asparagus harvesting technology. Computers and Electronics in Agriculture, 1997; 16(2): 137-145.

[31] Carter C, Ball T, Ward E, Fuchs S, Durfey J E, Cavalieri R P, et al. Performance and economic analysis of a selective asparagus harvester. ASABE, 2007; 23(5): 571-577.

[32] Edan Y. Design of an autonomous agricultural robot. Applied Intelligence, 1995; 5(1): 41-50.

[33] Edan Y, Rogozin D, Flash T, Miles G E. Robotic melon harvesting. IEEE Transactions on Robotics and Automation, 2000; 16(6): 831-835.

[34] Fogila M, Reina G. Agricultural robot for radicchio harvesting. Journal of Field Robotics, 2006; 23(6): 363-377.

[35] Raparelli T. Development of a new harvesting module for saffron flower detachment. Romanian Review of Precision Mechanics, Optics \&
Mechatronics, 2011; 39: 163-168.

[36] Sakai S, Iida M, Osuka K, Umeda M. Design and control of a heavy material handling manipulator for agricultural robots. Autonomous Robots, 2008; 25(3): 189-204.

[37] Zhang L B, Yang Q H, Bao G J, Wang Y, Qi L Y, Gao F, et al. Overview of research on agricultural robots in China. Int J Agric \& Biol Eng, 2008; 1(1): 12-21.

[38] Shamshiri R, Ismail W, Ishak W. Nonlinear tracking control of a two link oil palm harvesting robot manipulator. Int J Agric \& Biol Eng, 2012; 5(2) 9-19.

[39] Statistical handbook of Japan 2016: Statistics Bureau Ministry of Internal Affairs and Communications, Japan, 2016.

[40] Glodde A, Afrough M. Energy efficiency evaluation of an underactuated robot in comparison to traditional robot kinematics. Procedia CIRP, 2014 23: $127-130$.

[41] Roshanianfard A. Development of a harvesting robot for heavy-weight crop: Hokkaido University, 2018.

[42] Zhang C. Development of a multi-robot tractor system for farm work: Hokkaido University, 2017.

[43] Gosselin C M. Fundamentals of robotic mechanical systems: Theory, methods and algorithms. Jorge Angeles, Springer, New York, NY, 1997. ISBN 0-387-94540-7.

[44] Wang S-C, Hikita H, Kubo H, Zhao Y-S, Huang Z, Ifukube $\mathrm{T}$. Kinematics and dynamics of a 6 degree-of-freedom fully parallel manipulator with elastic joints. Mechanism and Machine Theory, 2003; 38(5): 439-461.

[45] Karlik B, Aydin S. An improved approach to the solution of inverse kinematics problems for robot manipulators. Engineering Applications of Artificial Intelligence, 2000; 13(2): 159-164.

[46] Roshanianfard A, Noguchi N. Designing of pumpkin harvester robotic end-effector. 2017 The 3rd International Conference on Control, Automation and Robotics (ICCAR 2017); Nagoya, Japan: IEEE, 2017.

[47] Roshanianfard A, Noguchi N. Development of a heavyweight crop robotic harvesting system (HCRH). 2017 The 3rd International Conference on Control, Automation and Robotics: IEEE, 2017.

[48] Roshanianfard A, Noguchi N. Kinematics analysis and simulation of a 5DOF articulated robotic arm applied to heavy products harvesting. Tarim Bilimleri Dergisi-Journal of Agricultural Sciences, 2018; 24(1): 91-104

[49] Şirinterlikçi A, Tiryakioğlu M, Bird A, Harris A, Kweder K. Repeatability and accuracy of an industrial robot: Laboratory experience for a design of experiments course. The Technology Interface Journal, 2009.

[50] Shimon Y. Handbook of Industrial Robotic, 2nd Edition, 1999.

[51] Barati M, Khoogar AR, Nasirian M. Estimation and calibration of robot link parameters with intelligent techniques Iranian Journal of Electrical and Electronic Engineering, 2011; 7(4): 225-234.

[52] Balafoutis CA, Patel RV. Dynamic analysis of robot manipulators. Concordia University, Montreal, Canada: Springer Science and Business Media, LLC; 1991.

[53] Mitrovic D. Learning motor control for simulated robot arms University of Edinburgh, 2006.

[54] Miomir V. Applied dynamics of manipulation robots: Modelling, Analysis and Examples. Springer; 1989.

[55] FANUC CO. FANUC corporation official website. http://fanuc.co.jp/ eindex.html. Accessed on [2018-05-31]

[56] Yaskawa Inc. Yaskawa Motoman offical website https://www.motoman.com/. \Accessed on [2018-05-31]

[57] ABB. ABB official website. http://new.abb.com/. Accessed on [2018-05-31]

[58] DENSO Co. DENSO official website. https://www.denso.com/ global/en/. Accessed on [2018-05-31]

[59] FCA Group. Comau official website. http://www.comau.com/en/ Accessed on [2018-05-31]

[60] Kawasaki Heavy Industries Ltd. Kawasaki official website https://robotics.kawasaki.com/en1/. Accessed on [2018-05-31]

[61] OTC Daihen Inc. OTC Daihen official website. http://www.daihen-usa.com/. Accessed on [2018-05-31] 